\title{
1 Performance of Lightweight Hemp 2 Concrete with Alkali-Activated \\ 3 Cenosphere Binders Exposed to 4 Elevated Temperature
}

5 Shanaka Kristombu Baduge ${ }^{1 *}$, Priyan Mendis $^{1}$, Rackel San Nicolas ${ }^{1}$, Kate

6 Nguyen $^{2}$, Ailar Hajimohammadi ${ }^{1}$

$7{ }^{1}$ Department of Infrastructure Engineering, The University of Melbourne, VIC 8 3052, Australia

$9 \quad{ }^{2}$ School of Engineering, RMIT University, VIC 3001, Australia

$10 *$ kasun.kristombu@unimelb.edu.au

\section{Abstract}

12 This study investigates the performance of three different types of cenosphere as a lightweight 13 supplementary cementitious material for alkali-activated binder for lightweight carbon14 negative hemp-concrete for non-load bearing applications. Mechanical performance of hemp concrete exposed to three temperatures, room temperature (RT), $300{ }^{\circ} \mathrm{C}$ and $600{ }^{\circ} \mathrm{C}$ are studied using mechanical testing, thermogravimetric analysis (TGA) and Fourier-transform Infrared Spectroscopy (FTIR). Hemp concrete with cenosphere binder remained its integrity and showed a lower load carrying capacity even after exposure to elevated temperatures. Compressive strength capacity and elastic modulus of the samples reduced with the increase of temperature and shows the composite material is more suitable for non-load bearing application considering its mechanical behavior and fire requirements. The density, age, and type of cenosphere showed effects on mechanical properties at room temperature and elevated 
temperatures. The study shows that alkali activated cenosphere binders can potentially be a sustainable alternative to the lime binder.

Keywords: Hemp concrete; Elevated Temperature; Low-Carbon building material; Fire Resistance; Cenosphere; Alkali-activated Binder; Stress-strain behavior; Elastic modulus;

27 Compressive strength; Failure mechanisms; Lightweight

\section{Introduction}

Shiv made of stalk of the hemp plant, and in some cases, fibres which are by-products of hemp farming are mixed with lime binder to produce lightweight hemp concrete [1]. Due to porous cellular structure, the hemp shivs have light-weight, insulation properties, acoustic and good hygrothermal properties and it is used as a bio-lightweight aggregate [2-4]. Hemp concrete has industrial application such as non-load bearing wall, slab and roof panels. However, due to porous nature and lesser strength of hemp shivs, hemp-lime concrete has a lower compressive strength relative to its density compare to other types of lightweight concrete such as aerated concrete [5]. Therefore, hemp concrete is more suitable for non-load bearing applications where load bearing capacity is not significant but thermal and acoustic properties are more important [6-8]. Moreover, carbon emission analysis for hemp lime concrete shows that it has the ability to sequestrate $\mathrm{CO}_{2}$-around $1.5-2.1 \mathrm{~kg}_{\mathrm{CO} 2} / \mathrm{kg}$ (kilogram of carbon dioxide per kilogram of hemp concrete) [8-10] both the growing phase of hemp plant and in the curing process of lime, which absorbs $\mathrm{CO}_{2}$ from the atmosphere in the carbonization process. Even though production of lime involves two $\mathrm{CO}_{2}$ emission processes which are due to heating and calcination of limestone, it has a net negative carbon emission due to it is higher carbon sequestration rate within its life cycle. So that it considers as a carbon negative material $[11,12]$. In addition, by increasing the percentage of hemp shiv by $20 \%$, the thermal conductivity of the hemp concrete can be reduced by $67 \%$ [7] which will contribute to the reduction of energy 
consumption and carbon dioxide emission of buildings. Therefore, having a lower density with higher amount of hemp shiv and lower amount of binder results a higher thermal performance and decrease the operational energy and emissions.

In the experimental programs, binders such as starch [13], cement [13,14], clay $[13,15]$ metakaolin, and slag [15] are investigated for hemp concrete. In addition, mix of different binders consisted of organic and/or inorganic cementitious materials such as lime and cement, cement and magnesium oxide, lime and metakaolin, starch and magnesium oxide are studied [13,15-17]. In general, research showed that mechanical properties varied with the type of the binders and binders made of starch and cement showed relatively higher compressive strengths than the lime binder.

Even though hemp-lime concrete is a carbon negative material, lime, the binder has a higher embodied energy than cement, results in a range of 5.3-5.63 MJ/kg [18,19], and its heating and calcination emit $\mathrm{CO}_{2}$ in a range of $0.42-0.8 \mathrm{kgCO}_{2} / \mathrm{kg}$ of lime $[11,20]$ and $0.7 \mathrm{kgCO}_{2} / \mathrm{kg}$ [20], respectively. Therefore, using a binder with a lower carbon footprint and an embodied energy while sustaining the performance of hemp concrete can further increase the sustainability and reduce the environment impacts.

Cenosphere is a by-product of coal power plant and known as top ash, and it is considered as a lightweight environmentally-friendly raw material and filler with a good fire performance and thermal properties due to its gas-filled hollow nature [21,22]. Moreover, due to its cementitious behaviour it can use as a supplementary cementitious material (SCM) which can further enhance the mechanical properties of hemp concrete while keeping lightweight characteristics [22]. SCM such as cenosphere (top-fly ash), fly ash and slag are by-products and do not emit large amount of $\mathrm{CO}_{2}$ or do not have high embodied energy like cement or lime [23-25]. Alkali activated binders made from fly ash and slag have lower carbon footprint and 
embodied energy compared to cement-based binders [26,27]. Therefore, alkali-activated binders consist of lightweight cenosphere, fly ash and slag could be an attractive alternative binder for hemp concrete for developing building elements with lower embodied energy and carbon footprint.

Fire resistance level (FRL) of non-load bearing walls is an important and panels must satisfy the required FRL [28]. The fire resistance of walls is assessed based on the time that the elements can maintain its structural adequacy/integrity/insulation when exposed to fire. For instant, internal partition wall of a residential building smaller than $300 \mathrm{~m}^{2}$ must have a fire rating level of 60/60/60 and -/60/60 for non-load bearing and non-load bearing walls according to AS 1530.4 [29], respectively. Since non-load bearing walls does not intend to carry any loads, structural adequacy is not tested for non-load bearing elements. Where the grading period is given in minutes for three criteria: structural adequacy, integrity, and insulation, respectively. However, fire performance of hemp concrete which contains organic hemp shiv and fibre is a major constraint to use hemp concrete in the construction industry. Lubos and Gregor [30] evaluated the fire resistance of hemp panels when exposed to standard timetemperature curves as given AS 1530.4 [29] and found that its performance is dependent on density and thickness of the panels. According to the experimental results [30], hempcrete panel requires a thickness of $400 \mathrm{~mm}$ to achieve FRL of -/60/60. In order to increase the FRL of hemp concretes, research [30] suggested increasing the thickness, and density of hemp concrete panels and providing an external protective layer such as $\mathrm{MgO}$ board or a rendering. However, increasing the density increase the weight of the panels, and providing thicker panels increases the wall thickness and reduces the floor area. Experimental program [16] to evaluate the fire reaction of low density (LD) and medium density (MD) hemp concrete panels according to EN 13823 [31] carried out. The study found that LD and MD panels have a quite good resistant to the fire with a class "C-s2-d0" and "B-s2-d0", respectively. Class C is 
prescribed as limited contribution to fire with similar performance as phenolic foam while class

97 B contributed less to fire than class $\mathrm{C}$ and performs similarly to plaster boards with thin combustible cover. Researchers [32,33] reported that two fire tests on hempcrete walls subject to $135 \mathrm{kN}$ of vertical load according to BS EN 1365-1 [34] resisted for 73 minutes in respect

100 to integrity, insulation, and load-bearing capacity. As concluded by researchers [30,32], data

101 related to performance of hemp concrete exposed to fire or elevated temperature is limited though fire performance is critical for load bearing and non-load bearing elements.

103 As discussed, the fire performance of hemp concrete can be increased by increasing the amount of binder, thickness of wall, and type of binder so that it can act as a shield around the hemp shiv. The density can be increased through the compaction or increasing the amount of binder. However, adding more binder increases the density of hemp concrete and increase the weight.

107 Therefore, using a lightweight cenosphere binder (around 1400-1600 $\mathrm{kgm}^{-3}$ ) which is lighter

108 than lime (around 1750-1900 $\mathrm{kgm}^{-3}$ ) can produce lighter panels with higher binder content.

109 Experimental results from research [35] showed that increase of the amount of binder increases

110 the mechanical properties such as compressive strength and modulus of elasticity. Thus, using

111 a lighter binder can provide a higher binder content and can potentially improves mechanical

112 properties and fire performance while having a lower density. Therefore, performance of hemp

113 concrete with cenosphere-based binders exposed to high temperature is evaluated in this study.

\section{Experimental Program}

\section{$115 \quad 2.1$ Materials}

\section{$116 \quad 2.1 .1$ Cenosphere}

117 Three types of cenosphere available in the industry were used in the experimental program. In

118 this study, they are named as CEN, ESP, and POZ. The physical appearance of cenosphere 
119 sourced from three different sources are shown in Figure 1. Figure 2 shows the images of

120 scanning electron microscopy analysis. The cenosphere are thin-walled microsphere with a

121 shell thickness of 5 to $20 \mu \mathrm{m}$ and diameters in a range of $68-232 \mu \mathrm{m}$. Figure 3 shows the particle

122 size distribution of the cenospheres.

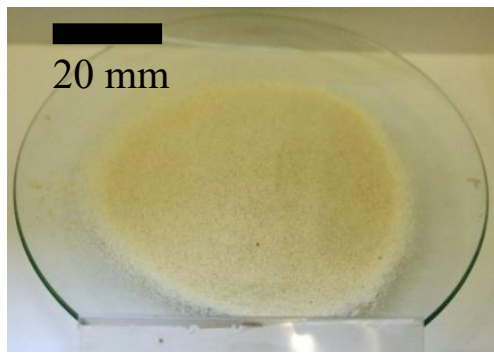

ESP

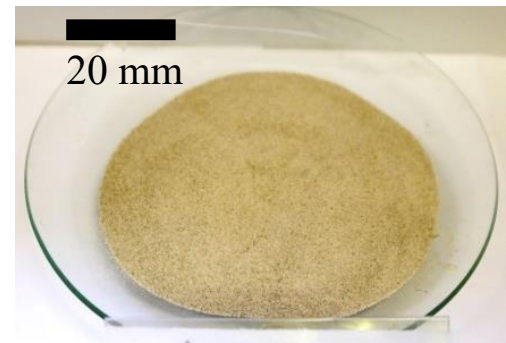

CEN

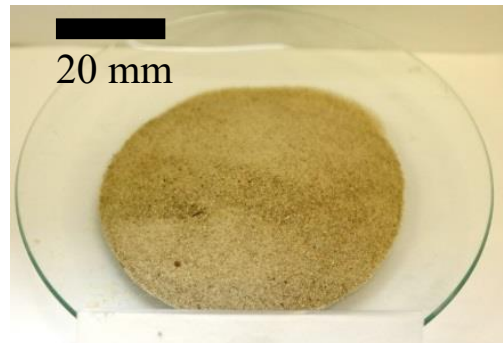

POZ

Figure 1: Three types of cenosphere
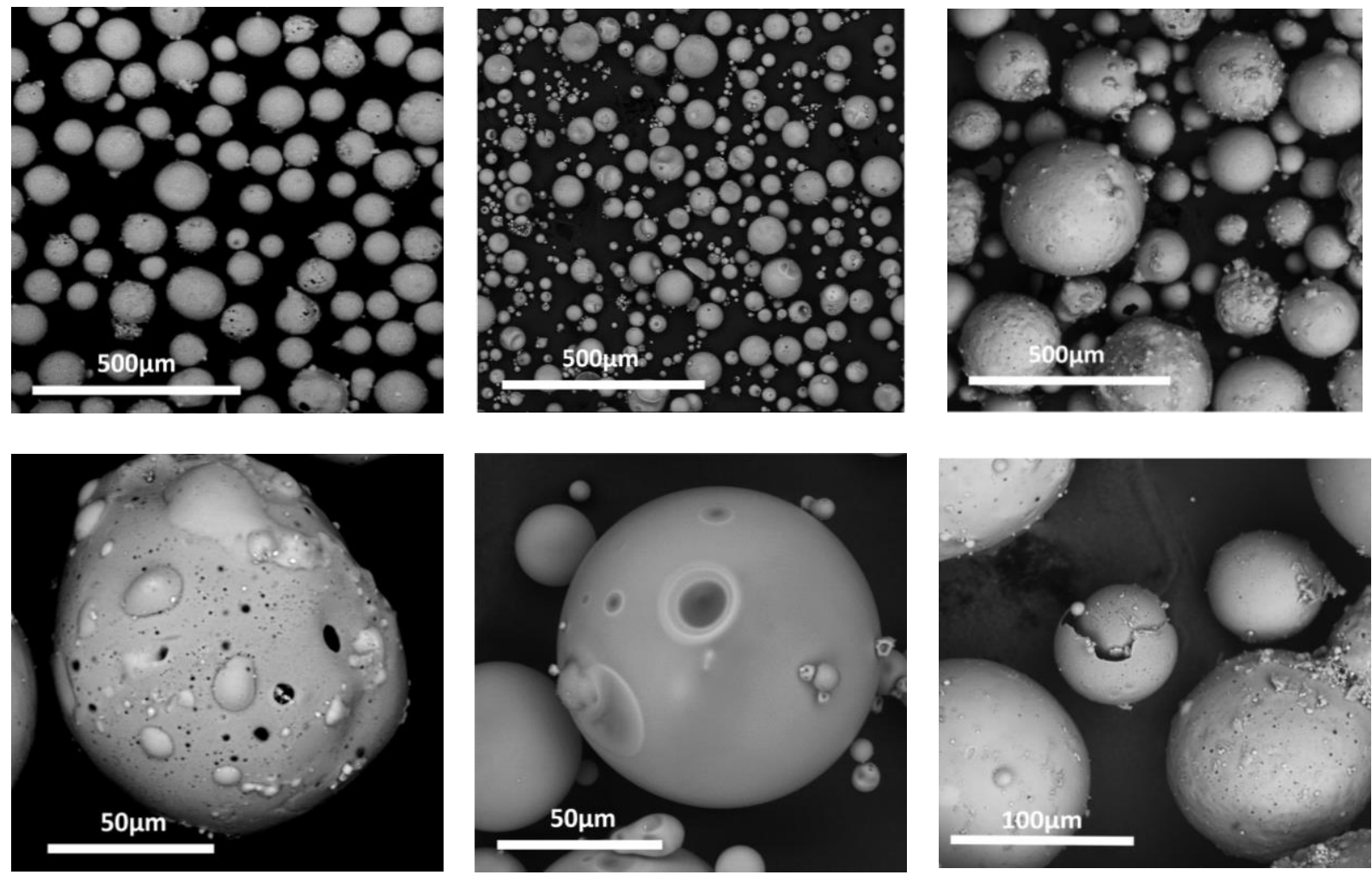


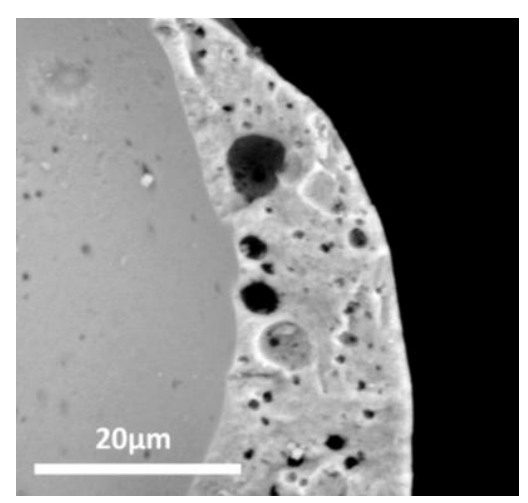

ESP

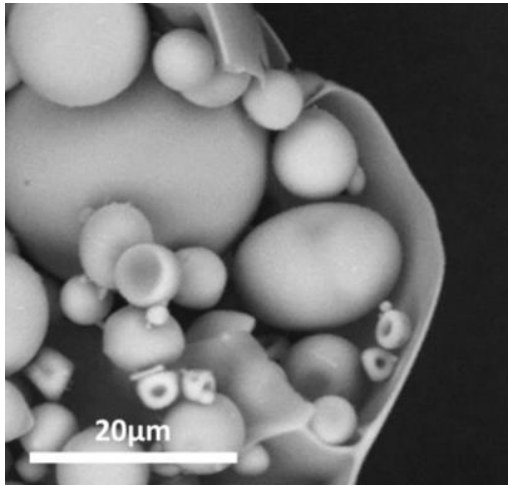

CEN

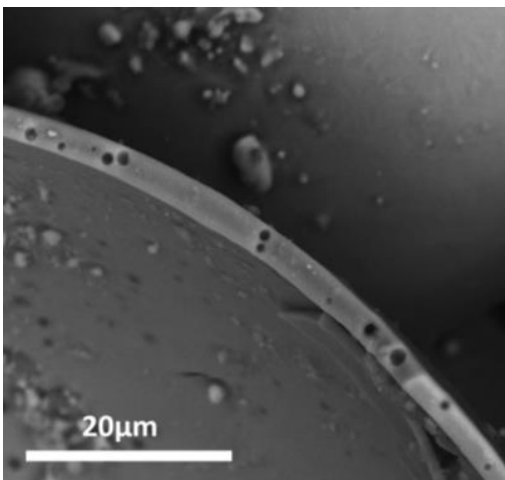

POZ

Figure 2: SEM images

124 Bulk density and true density of CEN, ESP, and POZ are given in Table 1. Chemical composition and phase identification of the cenosphere as given by XRD and XRF respectively are given in Table 2 .

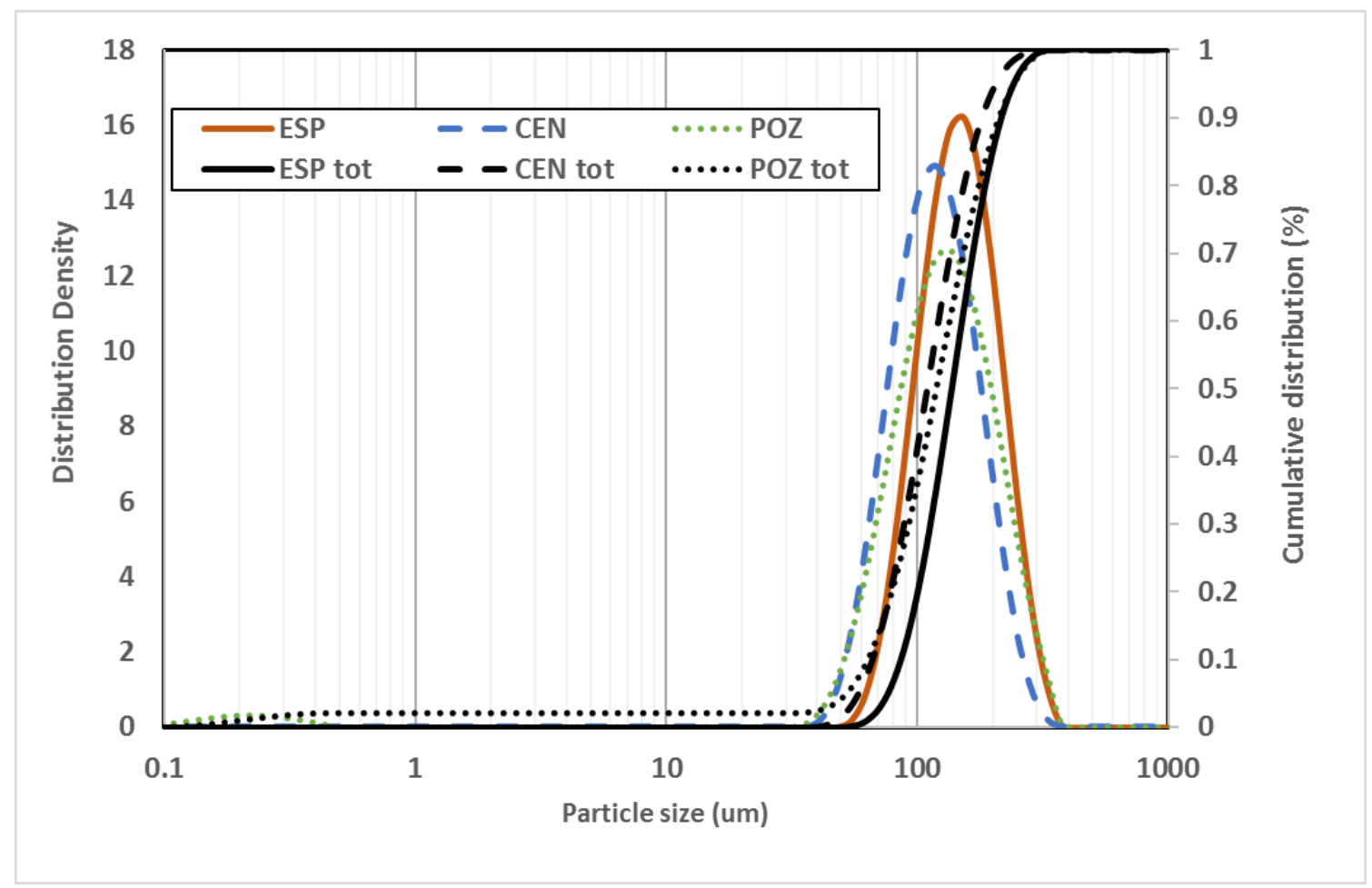

Figure 3: Particle size distribution of the cenospheres

Table 1: Physical Properties of cenosphere

\begin{tabular}{|l|c|c|c|c|}
\hline & Unit & ESP & CEN & POZ \\
\hline & & & & \\
\hline Bulk Density & $\mathrm{kgm}^{-3}$ & 350 & 480 & 150 \\
\hline
\end{tabular}




\begin{tabular}{|l|c|c|c|c|}
\hline True Density & $\mathrm{kgm}^{-3}$ & 630 & 830 & 330 \\
\hline Diameter Range & & & & \\
\hline \multicolumn{1}{|c|}{ Range } & $\mu \mathrm{m}$ & $91-232$ & $70-192$ & $68-231$ \\
\hline Average & $\mu \mathrm{m}$ & 147 & 117 & 129 \\
\hline Shell thickness & $\mu \mathrm{m}$ & $12-20$ & $3-5$ & $8-10$ \\
\hline Strength & $\mathrm{MPa}$ & 40 & 30 & 40 \\
\hline
\end{tabular}

129

Table 2: Chemical composition and phase identification of the cenospheres

\begin{tabular}{|l|c|r|r|}
\hline $\begin{array}{c}\text { Chemical Compound } \\
\text { (mass \%) }\end{array}$ & CEN & ESP & \multicolumn{1}{|c|}{ POZ } \\
\hline $\mathrm{Na}_{2} \mathrm{O}$ & 0.6 & 0.4 & 0.6 \\
\hline $\mathrm{MgO}$ & 0.8 & 1.0 & 0.9 \\
\hline $\mathrm{Al}_{2} \mathrm{O}_{3}$ & 29.4 & 29.1 & 26.8 \\
\hline $\mathrm{SiO}_{2}$ & 62.1 & 61.0 & 64.5 \\
\hline $\mathrm{P}_{2} \mathrm{O}_{5}$ & - & 0.1 & 0.2 \\
\hline $\mathrm{SO}_{3}$ & - & - & - \\
\hline $\mathrm{K}_{2} \mathrm{O}$ & 1.6 & 2.2 & 2.5 \\
\hline $\mathrm{CaO}$ & 0.7 & 0.7 & 0.5 \\
\hline $\mathrm{TiO}_{2}$ & 1.1 & 1.0 & 0.9 \\
\hline $\mathrm{MnO}$ & - & - & - \\
\hline Fe & - & 4.2 & 3.1 \\
\hline & 3.45 & & \\
\hline Mineral composition (wt $\%)$ & & & \\
\hline Mullite & 8 & 12 & 8 \\
\hline Quartz & 3 & 6 & 7 \\
\hline Amorphous phase & 88 & 82 & 85 \\
\hline
\end{tabular}

131

132 All three cenosphere seems to have a similar range of size between $40 \mu \mathrm{m}$ and $300 \mu \mathrm{m}$.

133 However, according to figure 3, CEN presents slightly smaller particles than POZ or EPS. this

134 difference in size could influence the reactivity of the binder by increasing nucleation sites and

135 hence increase the reactivity of the binder. Further, POZ have a small population of particle in

136 between 0.1 and $0.5 \mu \mathrm{m}$, such small population can hardly influence the behaviour of the

137 binder. Table 1 shows some properties of cenosphere using SEM images and nanoindentation,

138 respectively. 
139 X-ray diffraction spectra of the cenosphere materials are shown in Figure 4. The cenospheres

140 contained mullite $\left(\mathrm{Al}_{6} \mathrm{Si}_{2} \mathrm{O}_{13}\right)$ and quartz $\left(\mathrm{SiO}_{2}\right)$, and amorphous phase shown as "humps" in

141 the spectra. As shown in Table 2, CEN seems to present a higher content of amorphous

142 compounds which might increase its reactivity in cementitious system. High amounts of the

143 amorphous phase with $\mathrm{SiO}_{2}$ in the cenosphere particles raise the question of long-term stability

144 of the cenosphere in alkaline environment in cement composites.

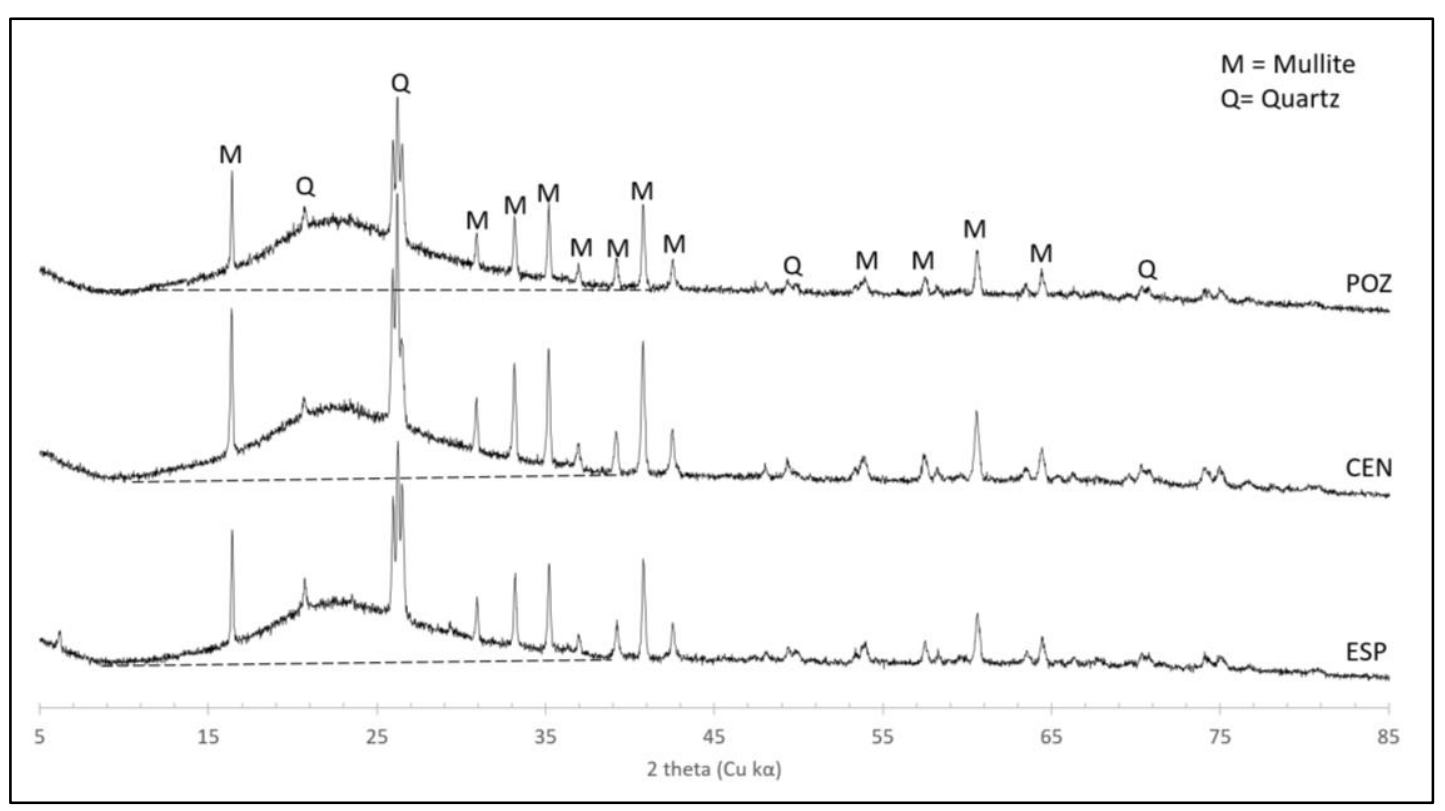

Figure 4 X-ray diffraction spectra of the cenosphere

\section{$145 \quad$ 2.1.2 Hemp Shiv}

146 The hemp shiv sourced from a local supplier with a bulk density of $188 \mathrm{kgm}^{-3}$ were used as the

147 lightweight bio-aggregate. The studies by researchers [35,36] showed that using fine hemp

148 particles improves the mechanical properties. Therefore, in this study smaller hemp particle in

149 a range of 1-5 $\mathrm{mm}$ are used, and larger particles are removed using $5 \mathrm{~mm}$ sieve. The moisture

150 content at Saturated Surface Dry (SSD) condition was 18\%: according to AS 1141.6 [37]

\section{$151 \quad$ 2.1.3 Cementitious Material}

152 A Class F fly ash complying with AS 3582.1 [38] and a slag cement satisfying the

153 specifications of AS 3582.2 [39] were used in the experimental program. Silica fume which 
satisfied the requirements as specified in AS 3582.3 [40]was used. A natural river sand with a fineness modulus of 2.6 and apparent particle density of $2610 \mathrm{~kg} / \mathrm{m} 3$ was used as the fine aggregate. Potassium hydroxide and potassium silicate $\left(\mathrm{KOH} / \mathrm{KSiO}_{3}\right)$ solution is used as an activator. The $\mathrm{KOH} / \mathrm{KSiO}_{3}$ solution had a concentration of $720 \mathrm{~g} / \mathrm{L}$. The solution consisted of $40 \% \mathrm{KOH}$ and $60 \%$ of $\mathrm{KSiO}_{3}$ by weight.

\subsection{Mix Design}

160 Three different alkali-activated binders using three different cenospheres-CEN, ESP, and POZ 161 were used to prepare the samples. Considering the cost of cenosphere, cenosphere is mixed 162 with fly ash, slag, silica fume, and sand. Hemp samples with a wet density around $1100 \mathrm{kgm}^{-3}$ 163 and dry density of $650 \mathrm{kgm}^{-3}$ were made using the three binders. Two different wet densities 164 are studied for ESP binder in order to investigate the effect of binder content. The study is part of developing a prefabricated composite lightweight-exterior cladding system as an alternative to brick veneer for residential building. In that case, panels must resist some impacts as well as fire. Considering the thickness of panels and ability to resist impact loadings, a higher-densities such as $900 \mathrm{kgm}^{-3}$ and $1200 \mathrm{kgm}^{-3}$ were considered. The composite panel consists of two layers of higher density hemp and lower-density hemp. Therefore, reduction in thermal performance due to higher densities will be compensated by the lower-dense hemp layer of the composite panel.

172 In order to get the lower density mix, ESP-900 half of the binder of Mix 01 is used for Mix 02.

173 With the compaction of 0.7 , final dry density of $1200 \mathrm{kgm}^{-3}$ and $900 \mathrm{kgm}^{-3}$ were expected for higher and lower density samples, respectively. The mix design proportions for CEN-1200, ESP-1200, POZ-1200, and ESP-900 are given in Table 3: first term is representing the type of cenosphere in the binder, and second term represents the dry density at 14 days. 


\begin{tabular}{|c|c|c|c|c|c|c|}
\hline & Mix No & & Mix 01 & Mix 02 & Mix 03 & Mix 04 \\
\hline Materials & $\begin{array}{c}\text { True } \\
\text { Density } \\
\left(\mathrm{kg} / \mathrm{m}^{3}\right)\end{array}$ & Unit & ESP-900 & ESP-1200 & CEN-1200 & POZ-1200 \\
\hline Hemp shiv & 200 & $\mathrm{~m}^{3}$ & 1 & 1 & 1 & 1 \\
\hline Slag & 2860 & $\mathrm{kgm}^{-3}$ & 95.7 & 191.3 & 191.3 & 191.3 \\
\hline Fly ash & 2290 & $\mathrm{kgm}^{-3}$ & 9.6 & 19.1 & 19.1 & 19.1 \\
\hline ESP & 630 & $\mathrm{kgm}^{-3}$ & 49.9 & 99.8 & & \\
\hline CEN & 830 & $\mathrm{kgm}^{-3}$ & & & 99.8 & \\
\hline POZ & 330 & $\mathrm{kgm}^{-3}$ & & & & 99.8 \\
\hline Silica fume & 2180 & $\mathrm{kgm}^{-3}$ & 20.4 & 40.8 & 40.8 & 40.8 \\
\hline Activator & 1120 & $\mathrm{kgm}^{-3}$ & 44.6 & 89.3 & 89.3 & 89.3 \\
\hline Sand & 2610 & $\mathrm{kgm}^{-3}$ & 138.4 & 276.8 & 276.8 & 276.8 \\
\hline Water & 1000 & $\mathrm{kgm}^{-3}$ & 79 & 158 & 158 & 158 \\
\hline Total water & 1000 & $\mathrm{~kg}$ & 96.9 & 193.7 & 193.7 & 193.7 \\
\hline Water/binder & & & 0.55 & 0.55 & 0.55 & 0.55 \\
\hline Hemp/binder & & & 1.14 & 0.57 & 0.57 & 0.57 \\
\hline Total weight & & $\mathrm{kg}$ & 659 & 1097 & 1097 & 1097 \\
\hline Wet Density & & $\mathrm{kgm}^{-3}$ & 659 & 1097 & 1097 & 1097 \\
\hline $\begin{array}{l}\text { Wet Density } \\
\text { after } \\
\text { Compaction }\end{array}$ & & $\mathrm{kgm}^{-3}$ & 1013 & 1567 & 1567 & 1567 \\
\hline
\end{tabular}

\subsection{Specimen Preparation}

179 Nine hemp cylindrical samples were prepared for each mix and in total thirty-six samples with

180 a diameter of $50 \mathrm{~mm}$ and height of $100 \mathrm{~mm}$ are prepared. Cylindrical samples were prepared

181 to test the compressive strength at room temperature (around $15-20{ }^{\circ} \mathrm{C}$ ), $300{ }^{\circ} \mathrm{C}$, and $600{ }^{\circ} \mathrm{C}$.

182 Samples names were given in the following format: CEN-1200-14d-300T-s1; where CEN,

$1831200,14 d$ and s1 stand for cenosphere type, dry density at 14 days, age of testing, heated

184 temperature and sample number, respectively. In sample naming, RT refers to room

185 temperature. Samples were air cured in the room temperature.

\subsubsection{Pre-soaking}

187 Due to the excess water absorption of hemp shiv binder was less workable and binder didn't

188 have enough water for the alkali-reaction. Considering that, the hemp shiv was soaked for 24 hours by a $\mathrm{KOH} / \mathrm{KSiO}_{3}$ solution at temperature around $20{ }^{\circ} \mathrm{C} . \mathrm{KOH} / \mathrm{KSiO}_{3}$ solution with a

190 concentration of $228 \mathrm{~g} / \mathrm{L}$ is selected for pre-soaking so that it is similar to the concentration of 191 the final mix where water and activator solution added together. The soaked hemp was strained 
and dried until it became to SSD condition. A similar method was used by Huiskes et al [5] for porous lightweight aggregates with higher absorption and Sedan et al. [41] presented that alkaline treatment on hemp increased the mechanical properties, indicating that interfacial

195 bonding is improved.

\subsubsection{Mixing and Compaction}

197 Dry mix of slag, fly ash, silica fume and sand were poured into the Hobart mortar mixer and 198 mixed for three minutes at a low-speed of $25 \mathrm{rpm}$ in order to get a uniform dry mix. The 199 activator solution was poured into the mixer and mixed for another one minute at low speed. 200 Half of soaked hemp shiv and water was added and mixed for another three minutes at $50 \mathrm{rpm}$.

201 Finally, the remaining amount of hemp was added and mixed for three minutes at $50 \mathrm{rpm}$. 202 Cylindrical moulds $(50 \times 100 \mathrm{~mm})$ were filled with hemp concrete mix and compacted. The 203 compaction is done in three layers using a rod with a diameter, height and mass of $25 \mathrm{~mm}, 75$ $204 \mathrm{~mm}$, and $280 \mathrm{~g}$, respectively. Ten drops from $25 \mathrm{~mm}$ height were given for each layer for the compaction. According to the trials, the compaction ratio in a range of $0.65-0.7$ are achieved for higher and lower density samples, respectively. Wet densities of samples were measured after casting. After 7 days, the samples were demoulded and cured in a temperature around 20 ${ }^{\circ} \mathrm{C}$ in an oven for 14 days then samples were kept in room temperature. After 14 and 56 days, dry densities of samples were calculated prior to testing.

\subsubsection{Heating}

211 Some of the samples were heated up to $300{ }^{\circ} \mathrm{C}$ and $600{ }^{\circ} \mathrm{C}$ using an oven for 90 minutes. The temperature curve for heating process is given in the Figure 5. In terms of heating samples up to $300{ }^{\circ} \mathrm{C}$, the temperature in oven took 30 minutes to reach $300{ }^{\circ} \mathrm{C}$ at a rate of $10^{\circ} \mathrm{C} / \mathrm{min}$ and

214 remained $300{ }^{\circ} \mathrm{C}$ for 60 minutes before natural cooling in the oven TO room temperature.

215 Temperature of $300{ }^{\circ} \mathrm{C}$ was selected because TGA results showed that evaporation of excess water and burning of hemps shiv ends around $300{ }^{\circ} \mathrm{C}$. The heating rate and the maximum 
219 FRL, heating time was selected as 90 minutes. Samples were weighted before and after heat

220 treatment in order to measure the mass loss. Figure 6 shows the nature of the samples before 221 and after heating.

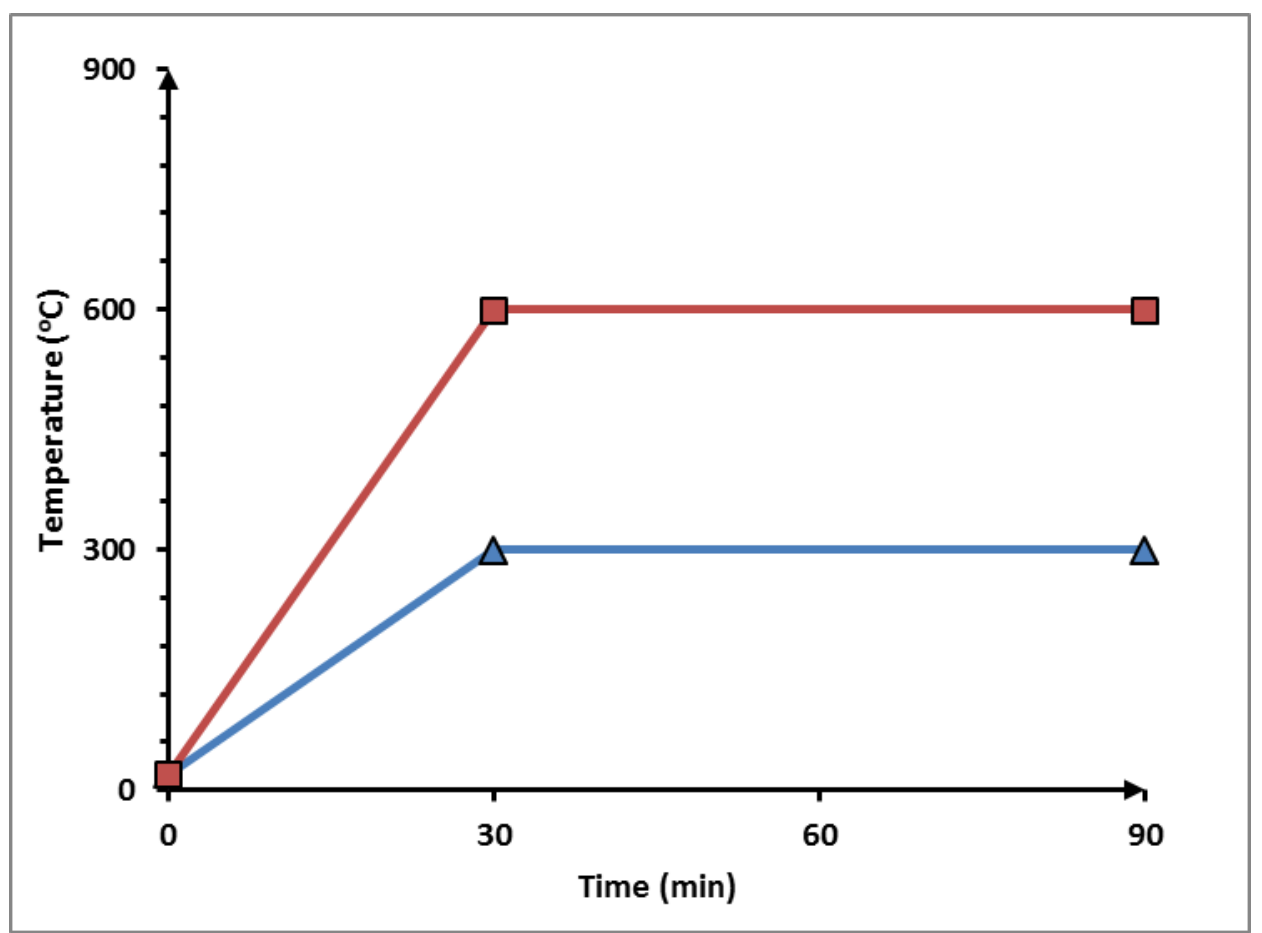

Figure 5: Heating curve

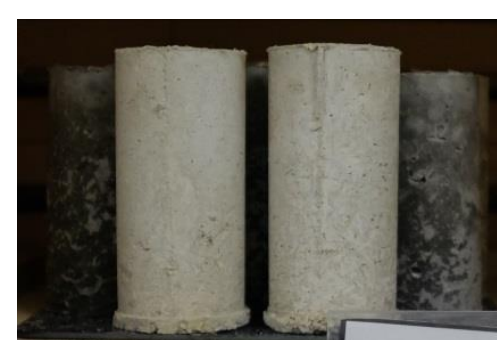

Before

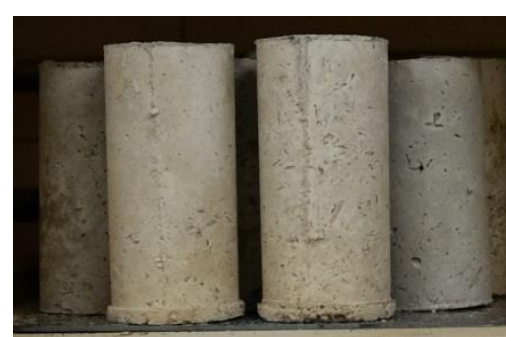

$300^{\circ} \mathrm{C}$

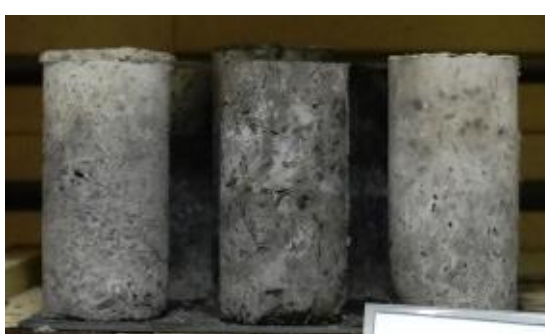

$600^{\circ} \mathrm{C}$

Figure 6: Samples before and after heating (CEN)

\subsection{Test Setup, Instrumentation, and Testing}

224 The compressive strengths of samples are measured using a universal testing machine, and load

225 versus displacement behaviour is captured. Displacement control loading method with a 
226 displacement rate of a $4 \mathrm{~mm} / \mathrm{min}$ was used. The test set up for the compressive strength testing

227 is shown in Figure 7. Microscopic images were taken from the cross-section of the samples at

228 room temperature by a Leica M205FA automated microscope to compare the interfacial

229 bonding characteristics in three groups of samples.

\subsubsection{Compressive Strength and Elastic Modulus}

231 The samples were tested at 14 days and 56 days so that time-dependent behaviour can be

232 observed. Compressive strength at 14 days selected in order to evaluate early strength with

233 excess moisture content and 56 days selected in order to evaluate the properties where excess

234 moisture is evaporated. Also, compressive strength of cenosphere binders at 14 days and 56

235 are evaluated to observe the variation of properties with the time and compare results with

236 properties of hemp concrete. Proof stress of $0.1 \%$ is used to calculate the compressive strength

237 and elastic modulus of hemp concrete is evaluated using stress-strain curve.

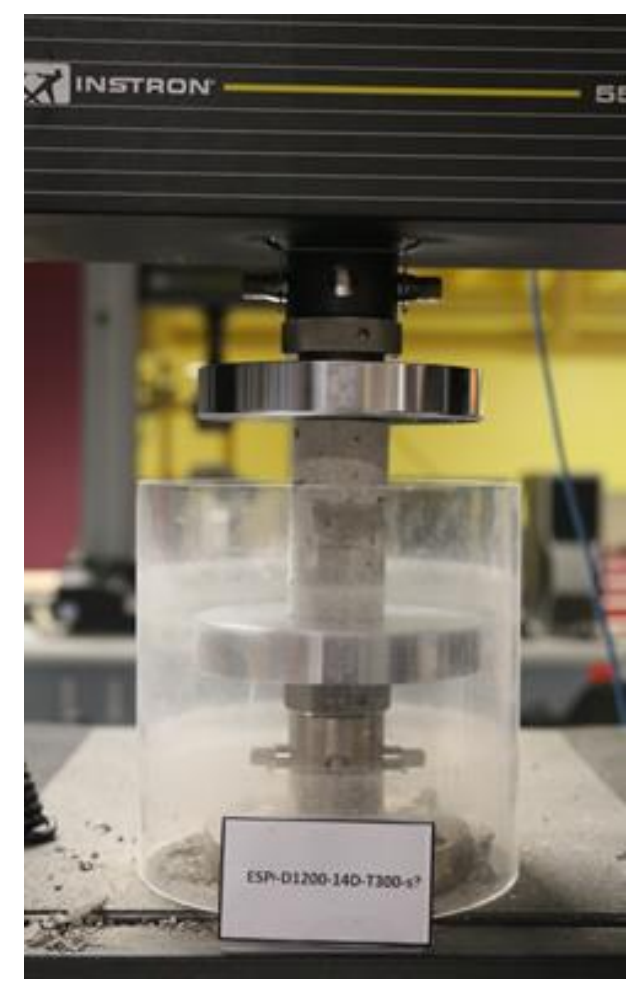

Figure 7: Test set-up 


\subsection{Fourier transform infrared spectroscopy}

239 Attenuated Total Reflectance Fourier Transform Infrared Spectroscopy (ATR-FTIR) is used to

240 analyse the chemical bonding structure of the samples at room temperature and after exposure

241 to $600^{\circ} \mathrm{C}$ using a Varian FTS 7000 FT-IR spectrometer, with a Specac MKII Golden Gate

242 single reflectance diamond ATR attachment with KRS-5 lenses. Absorbance spectra are

243 collected with a 4000-400 cm-1 wavenumber at a resolution of $2 \mathrm{~cm}-1$ and a scanning speed

244 of $5 \mathrm{kHz}$ with 64 scans.

\section{$245 \quad$ 2.5.1 Thermogravimetric analysis}

246 Thermo-gravimetric analysis was conducted in a thermos-gravimetric analyser (Perkin-Elmer

247 Pyris). Blank experiments were performed to achieve the baselines and then calibrated with

248 samples after testing. For each test, sample of $35-40 \mathrm{mg}$ was loaded to the ceramic crucible

249 of the analyser and heated from $30^{\circ} \mathrm{C}$ to $1000^{\circ} \mathrm{C}$ with the heating rate of $10^{\circ} \mathrm{C} / \mathrm{min}$. For this

250 analysis, the heating chamber was ventilated with Air at the flow rate of $80 \mathrm{~mL} / \mathrm{min}$.

\section{Results, Analysis and Discussion}

\subsection{Microscopic analysis of hemp concrete}

253 Figure 8 shows the microscopic images of the hemp concrete at the room temperature. The

254 cross section of the samples shows the interfacial bonding between the binders and hemp

255 particles. Comparing the gap between the binder and hemp particles shows some differences

256 between the interfacial bonding with hemp. POZ binder shows the biggest gap at the interface

257 followed by the EPS which also shows an air gap at the interface. CEN samples show the best

258 interfacial bonding with minimum gap between the hemp particles and the binder. 


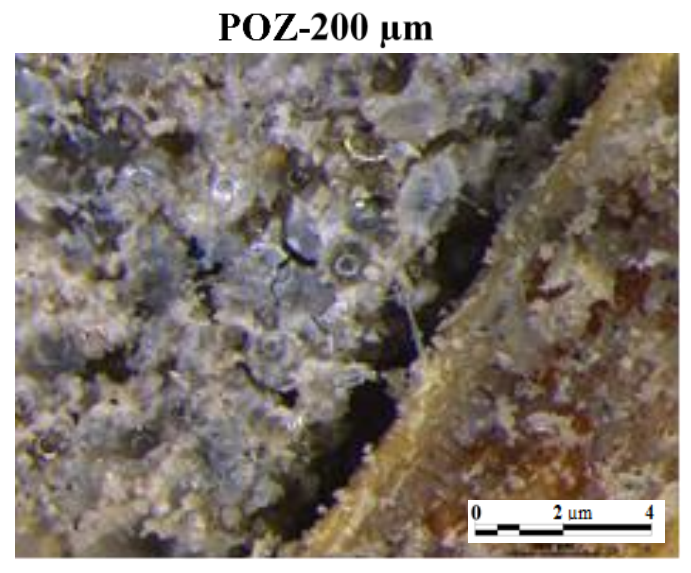

EPS-200 $\mu \mathrm{m}$
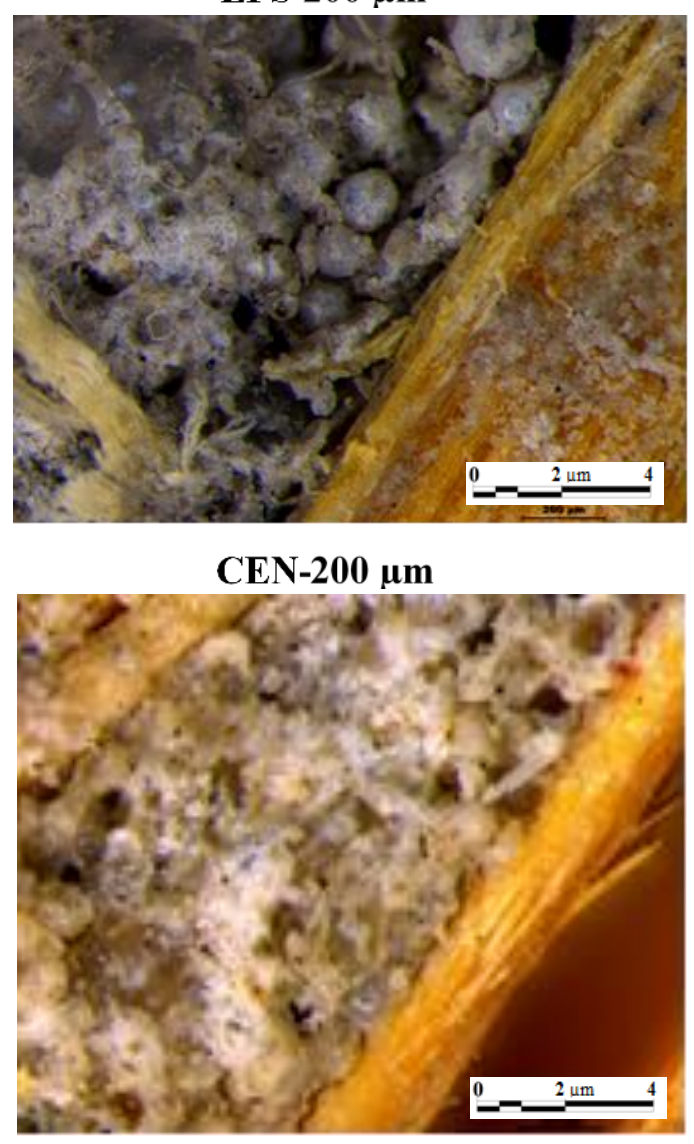
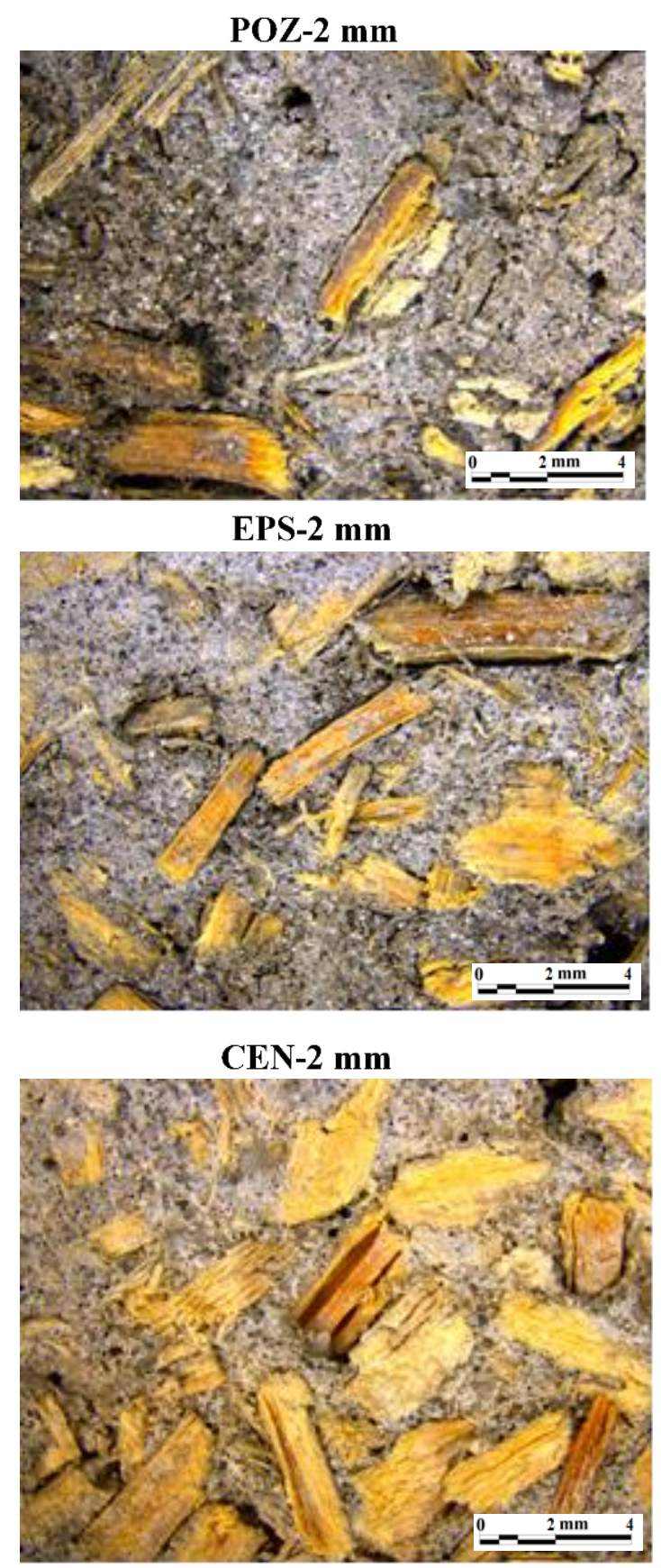

Figure 8. Microscopic images of the cross-section of samples at room temperature

\subsection{Mechanical Properties of Hemp Concrete}

\subsubsection{Variation of Density with Age and Temperature}

261 Table 4 shows the density of binders and hemp concrete at different stages. Wet density of

262 hemp concrete is approximately similar for Mix 1, 3, and 4 and lower for Mix 2 which has a 
263 lower-binder content. The dry densities of samples decreased with the time due to evaporation

264 of excess moisture. Therefore, mix design of hemp concrete for different densities shall account

265 the density variation with the time due to evaporation of excess moisture. At 14 days, there

266 wasn't a significant difference in density for the mixes. However, at 56 days, CEN showed a

267 lower density relative to ESP and POZ Mixes.After heating, the density is further reduced due

268 to evaporation of trapped moisture and burning of hemp samples. The density decreases with

269 the increase of temperature.

Table 4: Density of mixes

\begin{tabular}{|c|c|c|c|c|c|c|c|}
\hline \multirow{3}{*}{ Sample Id } & \multirow{3}{*}{$\begin{array}{l}\text { Wet } \\
\text { Density }\end{array}$} & \multicolumn{4}{|c|}{ Hemp concrete } & \multicolumn{2}{|c|}{ Binder Only } \\
\hline & & \multicolumn{2}{|c|}{ Dry Density } & \multicolumn{2}{|c|}{ After Heating } & \multirow{2}{*}{$\begin{array}{c}\text { Dry } \\
\text { Density } \\
\text { (56d) }\end{array}$} & \multirow{2}{*}{$\begin{array}{c}\text { After } \\
\text { Heating }\end{array}$} \\
\hline & & 14 days & 56 days & 14 days & 56 days & & \\
\hline & \multicolumn{5}{|c|}{$\left(\mathrm{kgm}^{-3}\right)$} & \multicolumn{2}{|c|}{$\left(\mathrm{kgm}^{-3}\right)$} \\
\hline ESP-900d-RT & \multirow{3}{*}{1056} & \multirow{3}{*}{965} & \multirow{3}{*}{867} & - & - & 1554 & - \\
\hline ESP-900d-300 & & & & 696 & 709 & 1578 & 1268 \\
\hline ESP-900d-600 & & & & 588 & 550 & 1581 & 1185 \\
\hline ESP-1200d-RT & \multirow{3}{*}{1576} & \multirow{3}{*}{1172} & \multirow{3}{*}{1070} & - & - & 1554 & - \\
\hline ESP-1200d-300 & & & & 922 & 929 & 1578 & 1268 \\
\hline ESP-1200d-600 & & & & 838 & 885 & 1581 & 1185 \\
\hline CEN-1200d-RT & \multirow{3}{*}{1514} & \multirow{3}{*}{1128} & \multirow{3}{*}{988} & - & - & 1516 & - \\
\hline CEN-1200d-300 & & & & 840 & 905 & 1546 & 1320 \\
\hline CEN-1200d-600 & & & & 773 & 754 & 1579 & 1210 \\
\hline POZ-1200d-RT & \multirow{3}{*}{1554} & \multirow{3}{*}{1145} & \multirow{3}{*}{1083} & - & - & 1565 & - \\
\hline POZ-1200d-300 & & & & 898 & 926 & 1590 & 1364 \\
\hline POZ-1200d-600 & & & & 839 & 854 & 1604 & 1300 \\
\hline
\end{tabular}

\section{$271 \quad 3.2 .2$ Failure Mechanism and Compressive Strength}

272 Figure 9 shows the typical failure modes of hemp concrete for heated and non-heated samples.

273 The samples were crushed when load was applied and bulged-out with the increase of

274 deformation. For the lower density, samples were able to squeeze more relative to the samples

275 with higher density due to higher void ratio and hemp content. The failure mechanism is

276 different to the concrete samples because of crushing mechanism and different to typical cone

277 type failure for mortar and concrete. For sample exposed to elevated temperature couldn't go through large deformation and the failure was brittle than non-heated samples. As shown in 
279 Figure 9, non-heated sample did not spall or break into pieces when the test was carried out 280 and able to keep its integrity while undergoing large deformation. However, for heated sample 281 broke into pieces and spalled while the testing.

282 Figure 10 shows compressive strength of hemp concrete and binders for the cenosphere at 14 and 56 days. Table 4 concluded that the density of sample is changing with the time. The density of light-weight concrete is correlated to the compressive strength $[5,43]$. In order to give an accurate demonstration of compressive strength relative to the dry density, compressive strength plotted along with density using two Y-axes and a shared X-axis. For 14 days results, the samples with 1200 density had similar compressive strength. ESP-900 had the lowest strength which has the lower density or the binder content. At 56 days, higher compressive strengths were given by POZ and CEN mixtures, and it is aligned with the binder results because compressive strength of ESP binder reduces at 56 days and respective hemp mix gave a lower compressive strength. As shown in Figure 10, compressive strength of mixes decreased with the time. The compressive strength of ESP-1200 was significantly reduced at 56 days relative to other mixes. Similarly, compressive strength of ESP binder reduced at 56 days relative to 14 days results. The decrease of the compressive strength in cement-based sample including cenosphere has been observed before in the literature [44-46] and confirmed here. It can be explained as follows: Adding the cenosphere in a binder can develop a high strength for

297 a lower density. It can behave as a filler, hence increasing the density as well as a pozzolanic addition due to their chemical composition and amorphous nature. However, as the cenospheres are hollow, after a certain time, the surface of the shell is consumed, causing the structure to become disintegrated and the creation of microstructural cracks and shell less voids which in terms affects the strength and performance of the material. It has been observed in the literature [44-46] that a higher replacement of cenospheres have tortuous and cracked patterns, 
with the cracks going through the cenospheres as the weakest regions which shows the energy-

304 dissipating mechanism.

305 The compressive strength results showed that hemp concrete with CEN and POZ had 306 approximately similar results at 14 and 56 days for non-heated samples. The results concluded

307 that density and compressive strength of hemp concrete influenced by the type of cenosphere.

308 Also, compressive strength of hemp concrete reduced with the time and the percentage of

309 reduction was influenced by the types of the cenosphere though the compressive strength

310 increases in the binder for CEN and POZ mixes. Therefore, it can be assumed that binder may

311 not be the reason behind the decrease in compressive strength of hemp concrete. Density of

312 samples was reduced with the time due to evaporation of water which causes reduction in

313 density. Further reduction of density results from removal of pore water within the hemp shiv

314 can be a reason behind reduction in strength.

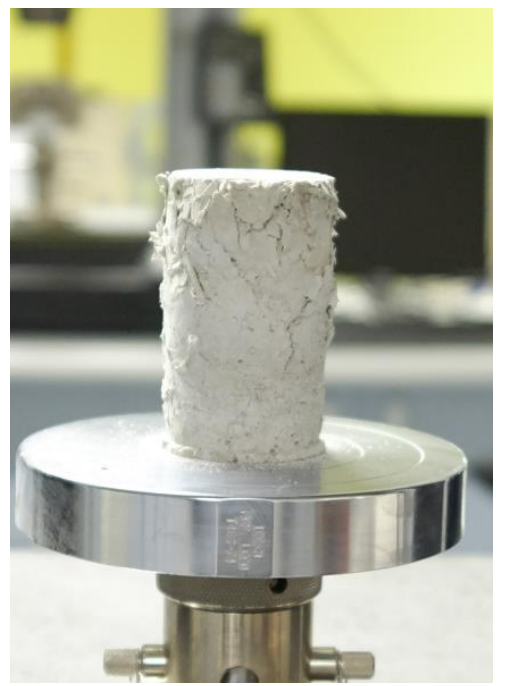

ESP-900d-56d-RT-s1

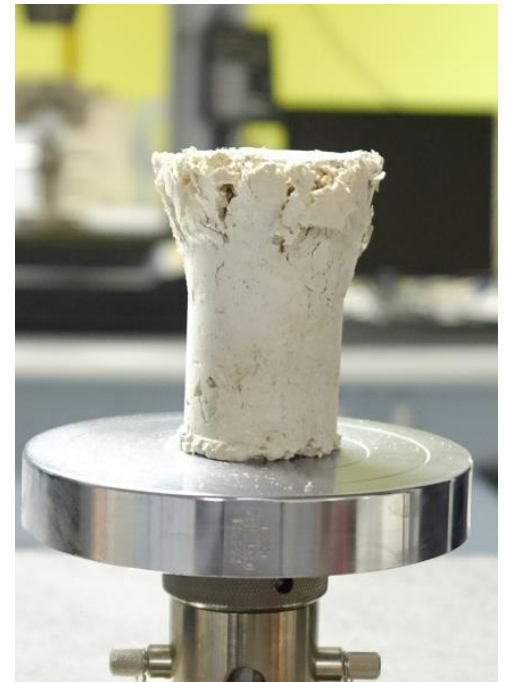

ESP-1200d-56d-RT-s1 

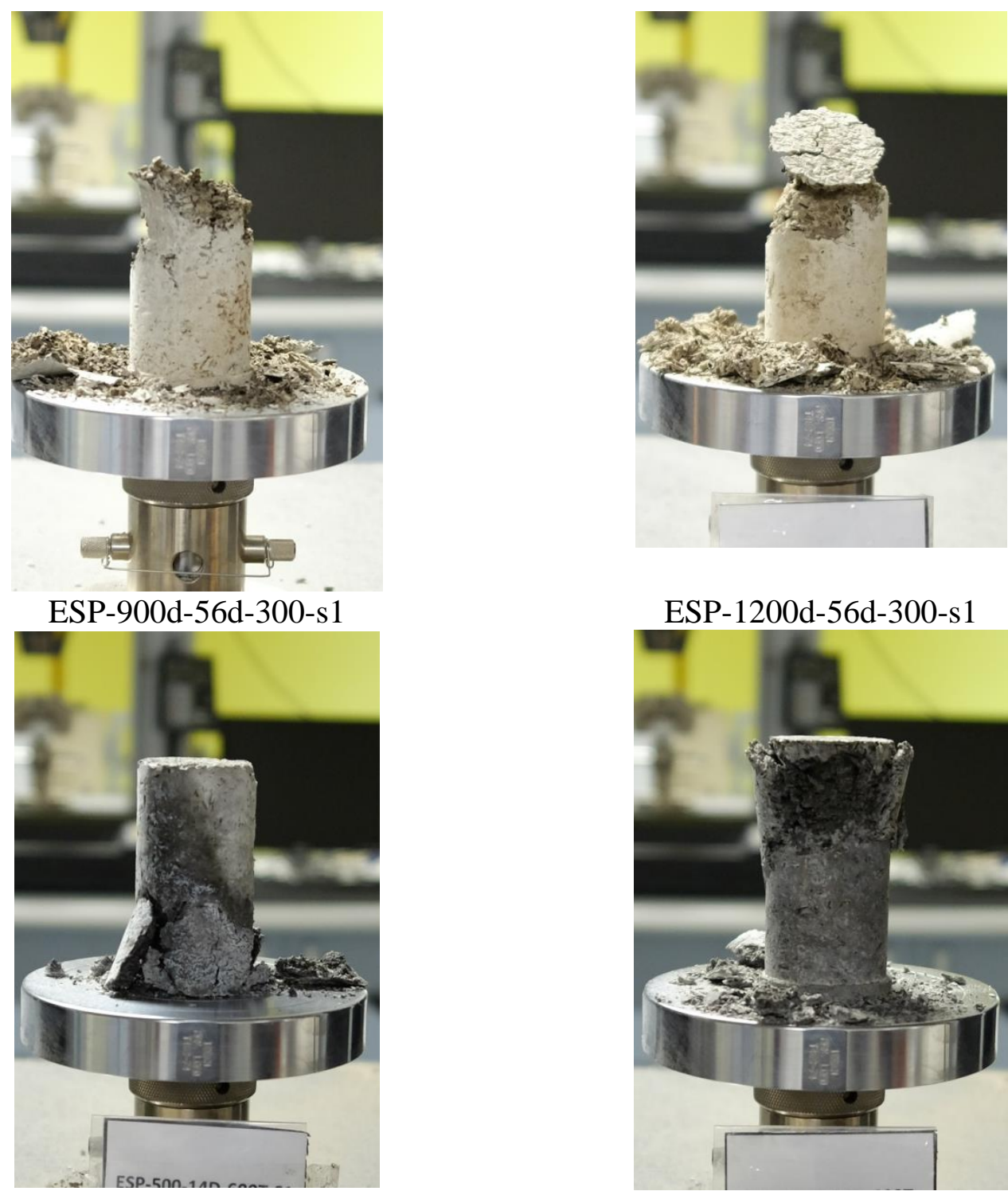

ESP-900d-56d-600-s1

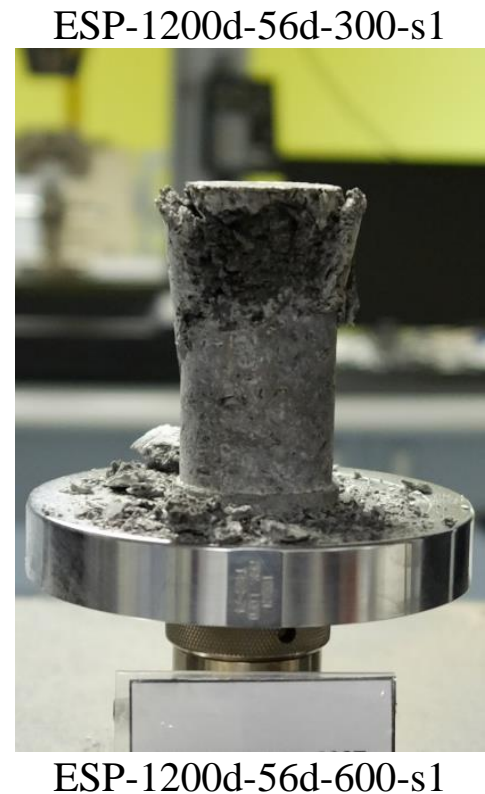

Figure 9 Failure mode of samples 


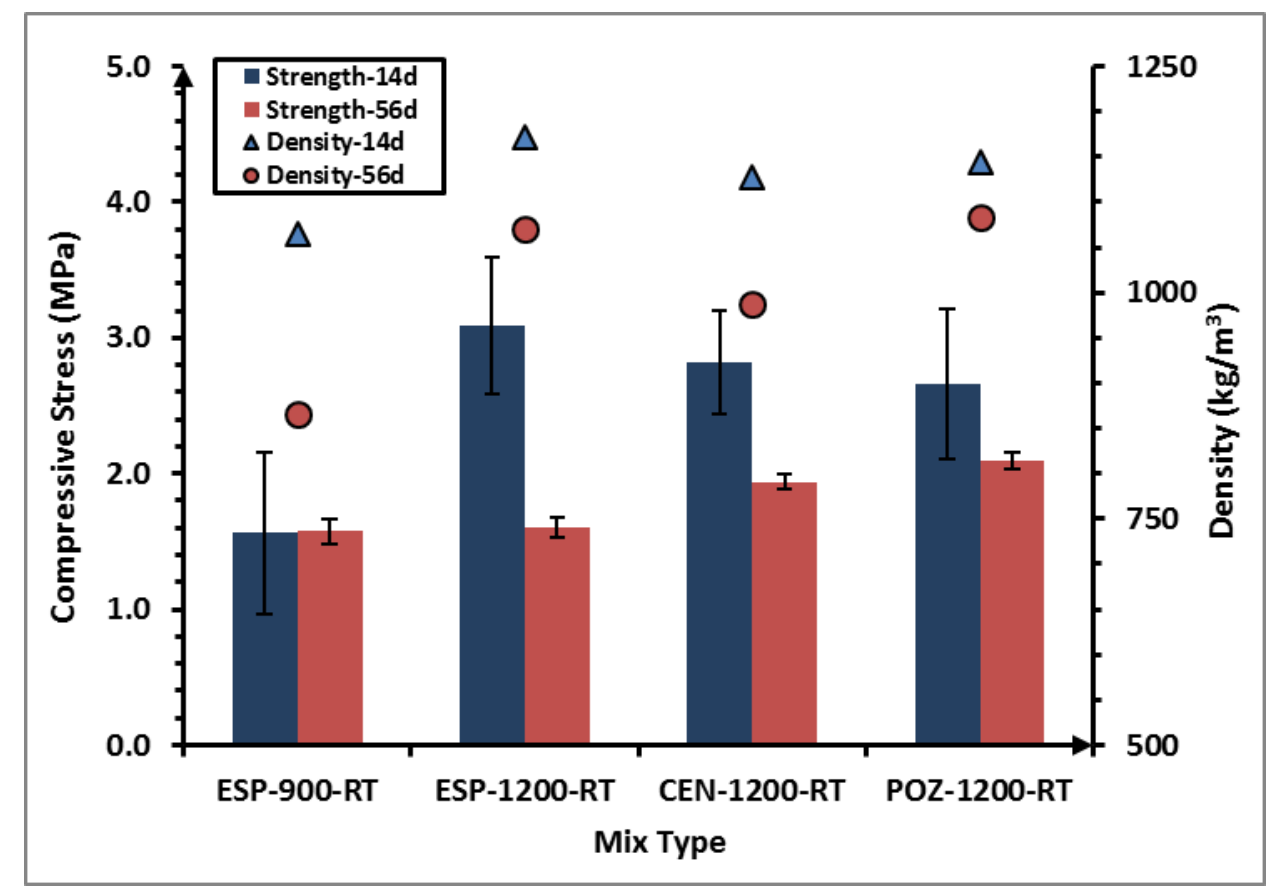

a). Hemp concrete

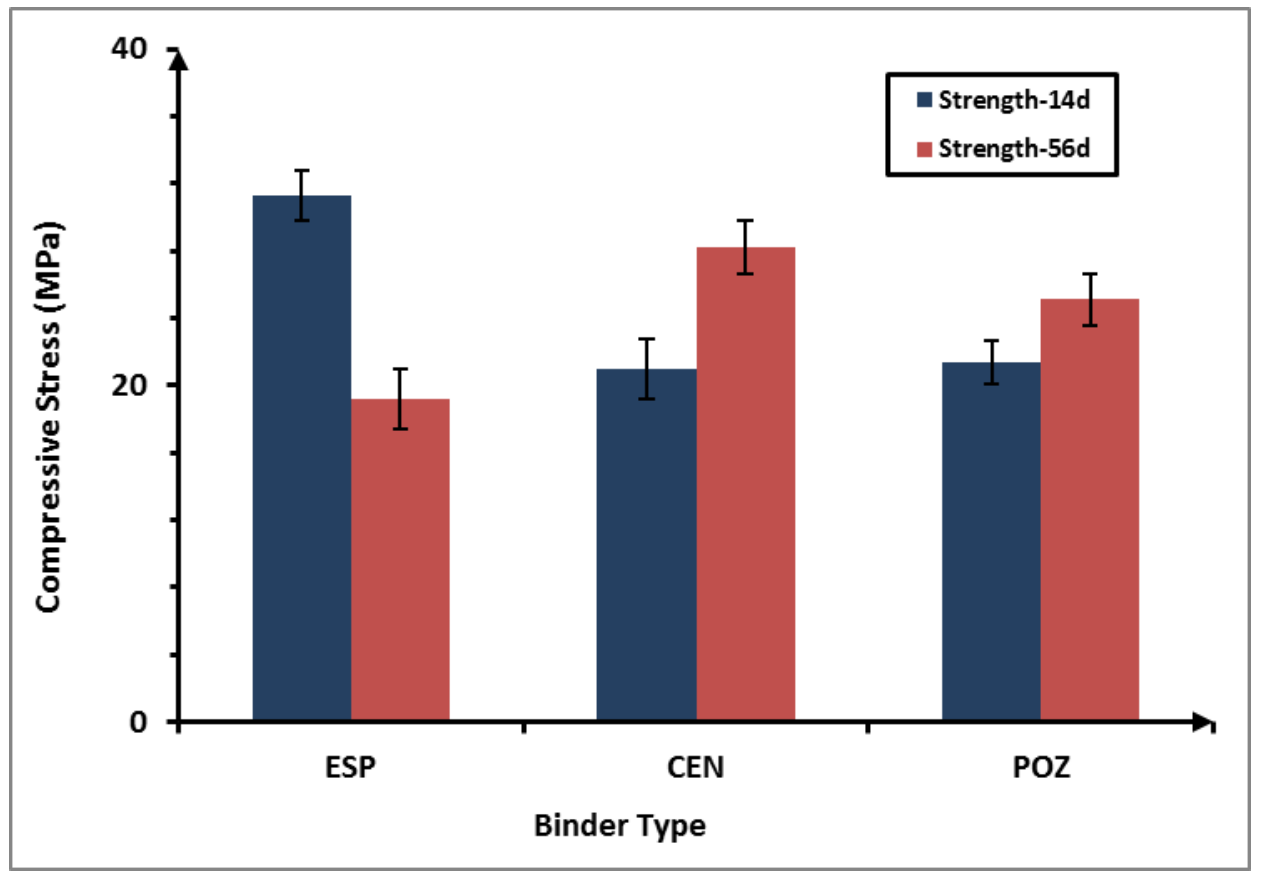

b). Binder -standard deviation

Figure 10: Compressive strength of hemp concrete and binders

317 Figure 11 shows the variation of compressive strength with the temperature after exposed to

318 elevated temperature. The compressive strength of samples exponentially decayed with the

319 increase of temperature. At 14 days, CEN had the highest compressive strength for heated

320 samples. In contrast, ESP showed highest compressive strength for non-heated samples. 
321 However, at 56 days, POZ showed the highest compressive strength for heated and non-heated samples. ESP-900 showed the lowest compressive strength for heated samples. This concluded that compressive strength after exposure to elevated temperature is dependent on density, types

324 of cenosphere and the age of the hemp concrete. Different lime binders are used in the literature with densities in a range of 1733-1989 $\mathrm{kgm}^{-3}$ and compressive strength in a range of 1.2-3.0 MPa [47-49]. Table 4 and Figure 10 showed that cenosphere binders have a lower density and similar strength range than the lime binders in the literature.

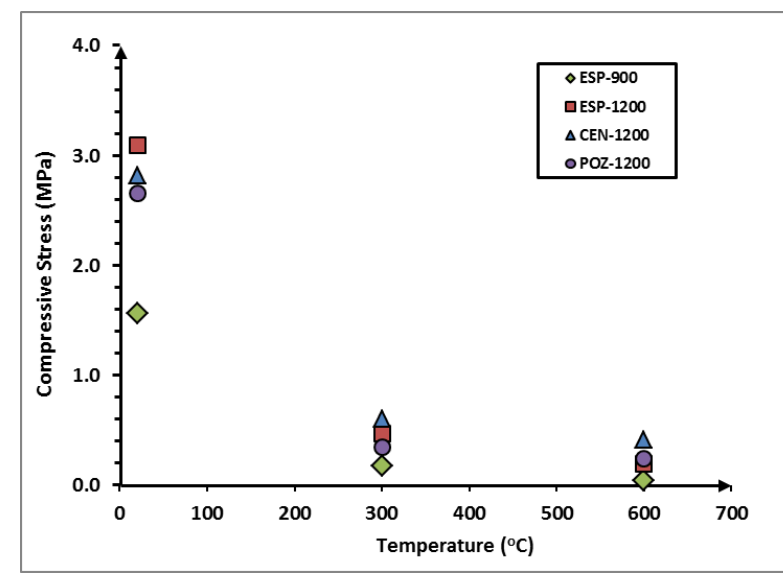

At 14 days

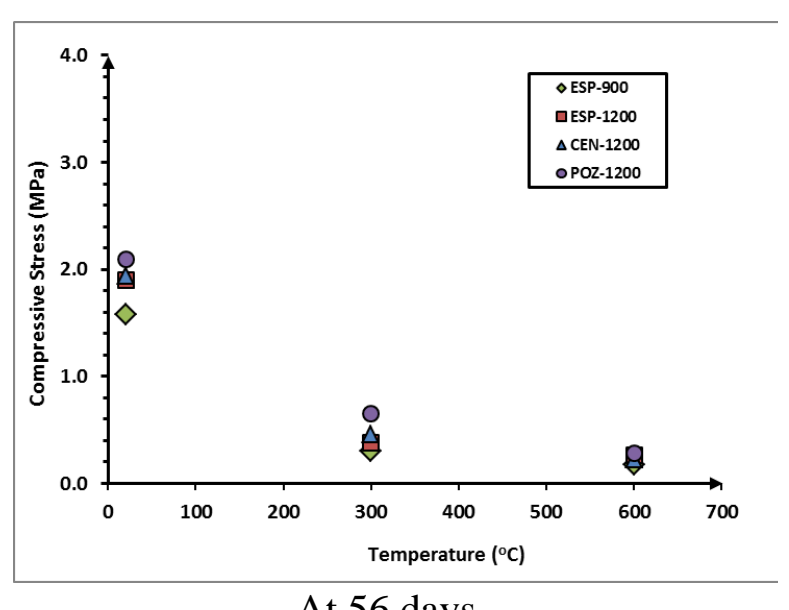

At 56 days

Figure 11: Compressive strength after exposure to elevated temperature

\subsection{Stress-Strain Behaviour and Toughness}

329 Stress-strain behaviour is an important mechanical property in order to evaluate structural behaviour, capacity and evaluate the suitability for load-bearing applications. As well as, it is used to evaluate the ductility and toughness which is an important characteristic for load bearing and non-load bearing. The toughness represents the ability to undergo large deformation and stored plastic energy until the fracture. This is important for both load bearing and non-load bearing structural element to evaluate its resilience in case of excessive deformation due to earthquakes, low-velocity impacts, and differential settlements. It must be noted that the failure of the sample happened due to crushing and failure was highly localized 
calculating strain using displacement and sample height may not represent the accurate strain of the sample. However, in this study for the comparison purposes, strain was calculated using full sample height. Figure 12 shows the general trend of stress-strain behaviour of mixes. The stress-strain behaviour shows that the sample with lower density, ESP-900 is more ductile than sample with higher density. Figure 12 shows that stress increases with the increase of displacement after yielding for ESP-900. Thus, stress hardening behaviour is shown by ESP900 at 14 days. However, at 56 days, ESP-900 showed a plastic behaviour with a plateau after the peak and didn't show a stress hardening. The stress-strain behaviour of ESP-900 was different to the typical stress-strain behaviour of concrete or mortar, and it didn't show a brittle behaviour with a descending branch after reaching to the peak. The ductile behaviour is suitable because plaster boards for exterior cladding elements such as cement, calcium silicate and gypsum boards are brittle and vulnerable to cracking. Lower density samples which has a lower binder content and a higher hemp shiv content had a higher ductility and can undergo large deformation without reduction in capacity. For higher density, post-peak branch of stressdisplacement curve was descending without an abrupt reduction in the stress. The result shows that steepness of the descending branch increases with the time and samples are more brittle at 56 days than 14 days. Stress-strain behaviour at 300 and $600{ }^{\circ} \mathrm{C}$ shows that strengths of samples reduce significantly with the increase of temperature. Table 5 shows the modulus of elasticity and toughness of the samples at 56 days. Toughness is calculated using $I_{10}$ and $I_{20}$ toughness indices as given in ASTM C 1018 [50]. Higher toughness index implies that material can

358 absorb energy and can plastically deform without fracturing. Stiffness and toughness of the samples decreased significantly with the increase of temperature. POZ-1200 had a higher toughness value than the other samples. Also, ESP-900 had a higher toughness values than ESP-1200 and CEN-1200 due to its higher deformability contrast to the lower strength. 
14 days

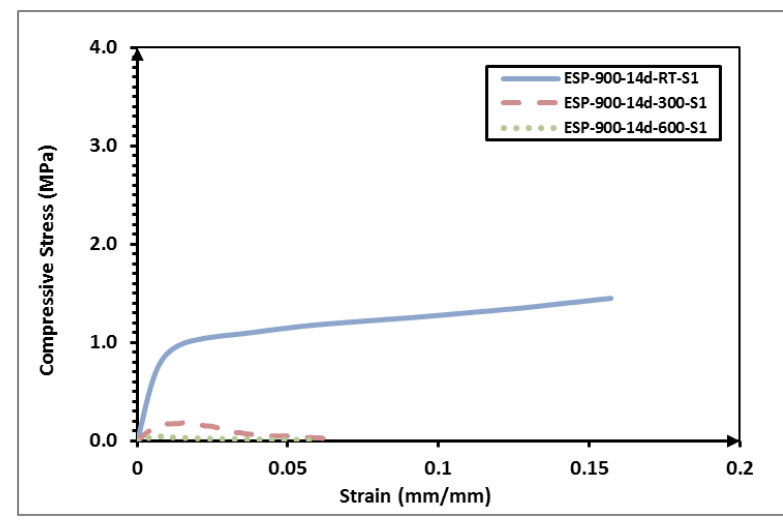

a.) ESP-900-14d

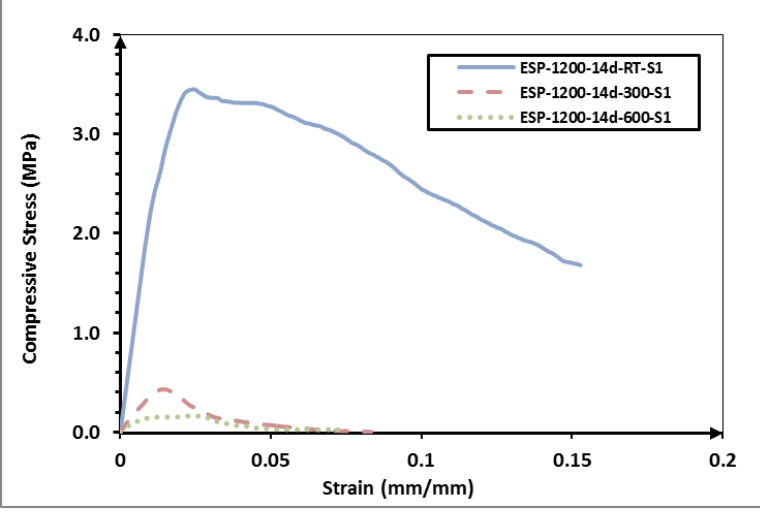

c.) ESP-1200-14d

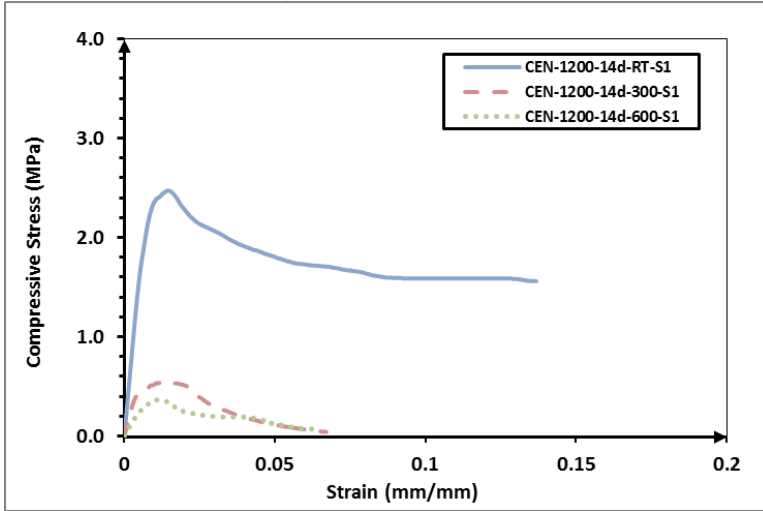

e.) $\mathrm{CEN}-1200-14 \mathrm{~d}$

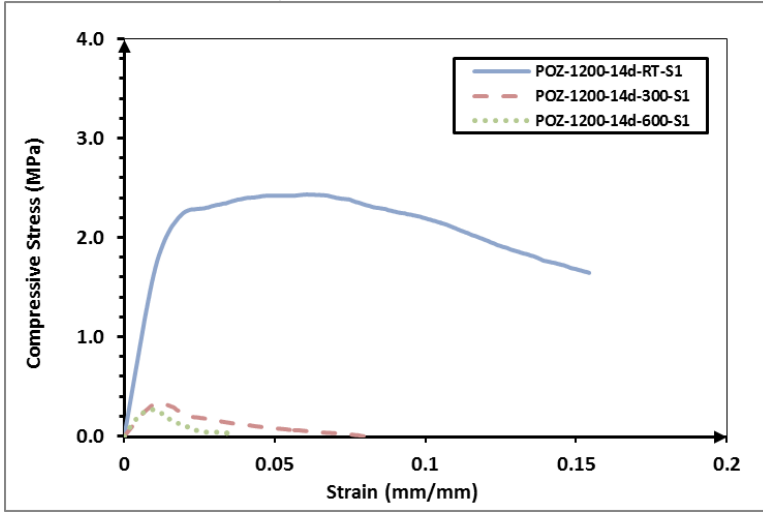

g.) POZ-1200-14d
56 days

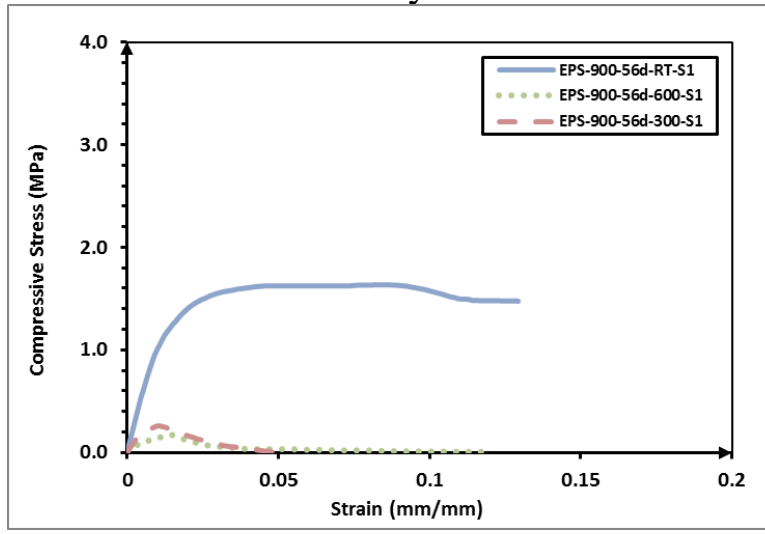

b.) ESP-900-56d

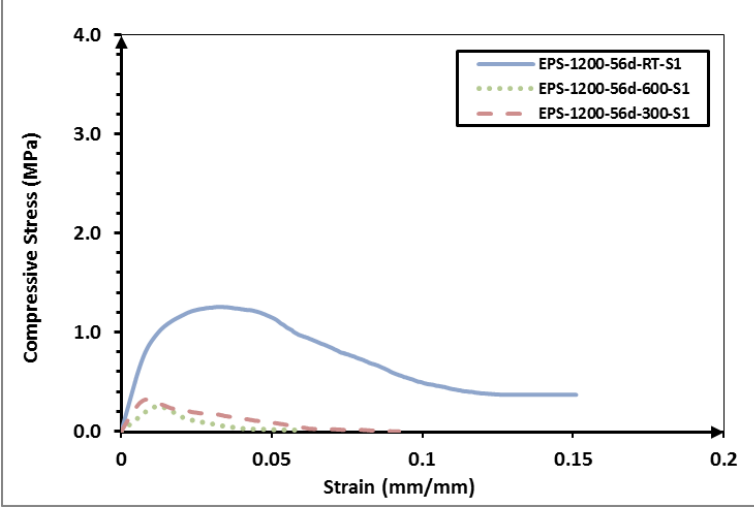

d.) ESP-1200-56d

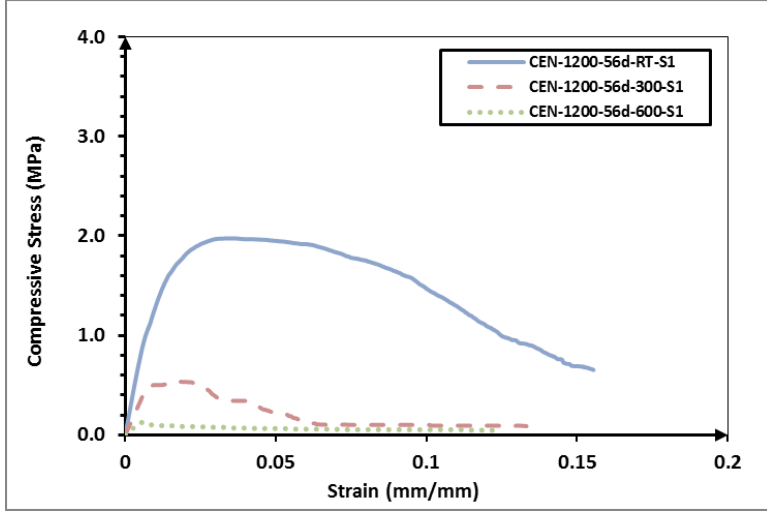

f.) $\mathrm{CEN}-1200-56 \mathrm{~d}$

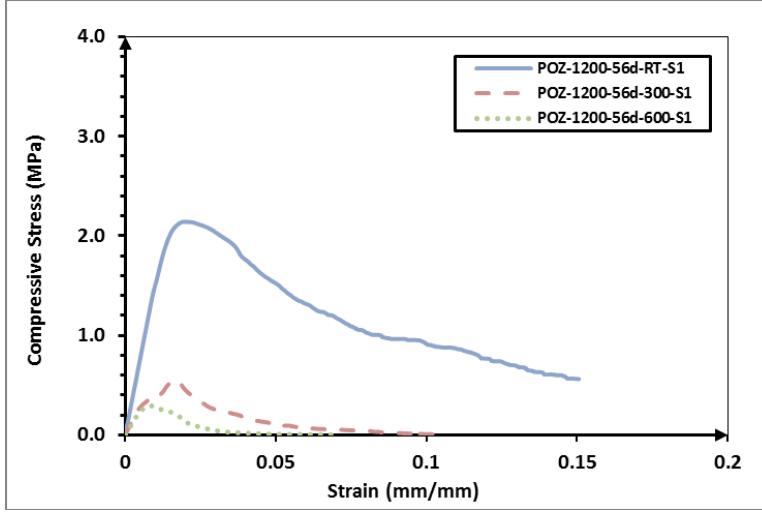

h.) POZ-1200-56d

Figure 12: Stress-strain behaviour at 14 and 56 days 
Table 5: Properties after exposure to elevated temperature

\begin{tabular}{|c|c|c|c|c|}
\hline \multirow[t]{2}{*}{ Sample name } & \multirow{2}{*}{$\begin{array}{c}\text { Temperature } \\
\left({ }^{\circ} \mathrm{C}\right)\end{array}$} & \multirow{2}{*}{$\begin{array}{c}\text { Modulus of } \\
\text { Elasticity (56d) } \\
\text { (MPa) }\end{array}$} & \multicolumn{2}{|c|}{$\begin{array}{c}\text { Toughness }(56 \mathrm{~d}) \\
(\mathrm{J} / \mathrm{J})\end{array}$} \\
\hline & & & $\mathrm{I}_{10}$ & $\mathrm{I}_{20}$ \\
\hline \multirow{3}{*}{ ESP-900 } & RT & 105 & 0.099 & 0.141 \\
\hline & 300 & 52 & 0.006 & 0.007 \\
\hline & 600 & 26 & 0.005 & 0.005 \\
\hline \multirow{3}{*}{ ESP-1200 } & RT & 94 & 0.084 & 0.084 \\
\hline & 300 & 54 & 0.012 & 0.012 \\
\hline & 600 & 21 & 0.007 & 0.007 \\
\hline \multirow{3}{*}{ CEN-1200 } & RT & 160 & 0.066 & 0.135 \\
\hline & 300 & 68 & 0.014 & 0.020 \\
\hline & 600 & 19 & 0.002 & 0.004 \\
\hline \multirow{3}{*}{ POZ-1200 } & RT & 158 & 0.112 & 0.170 \\
\hline & 300 & 95 & 0.012 & 0.015 \\
\hline & 600 & 43 & 0.006 & 0.007 \\
\hline
\end{tabular}

\subsection{Modulus of Elasticity}

366 Figure 13 shows the modulus of elasticity of hemp concrete for the mixes with different

367 cenospheres and two densities. Figure 13 shows the modulus of elasticity versus temperature

368 after exposure to the elevated temperature.

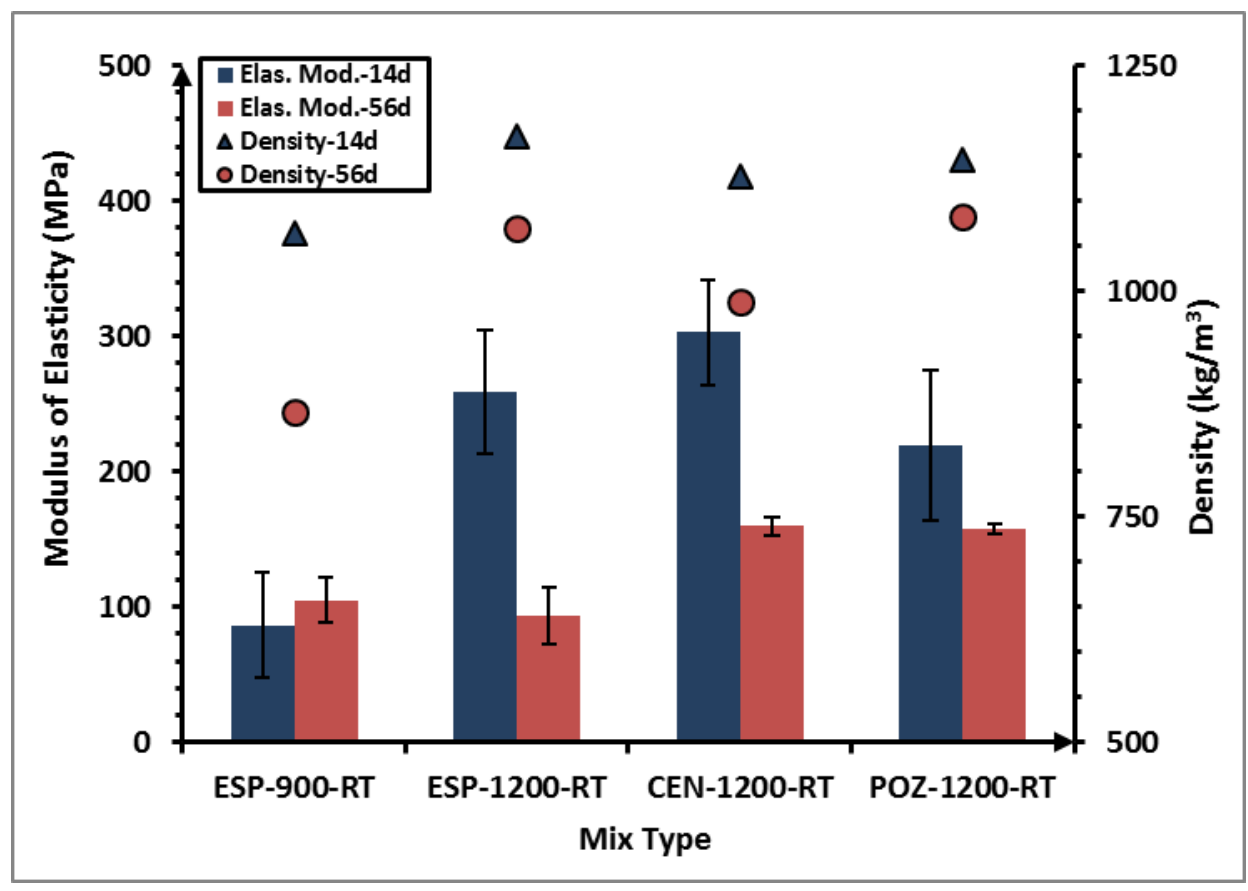

Figure 13: Elastic modulus hemp concrete and binders

369 The modulus of elasticity decreased with the increase of temperature. It appeared that modulus

370 of elasticity decreased with the time. Similar to the trend of compressive strength versus 
371 temperature, CEN and POZ mixes showed the highest modulus of elasticity at RT. POZ

372 showed highest modulus of elasticity when exposed to elevated temperature at 56 days. ESP-

3731200 mix showed lower modulus of elasticity versus temperature relative to other mixes at 56

374 days. The results concluded that modulus of elasticity for heated samples are dependent on age

375 and the type cenosphere.

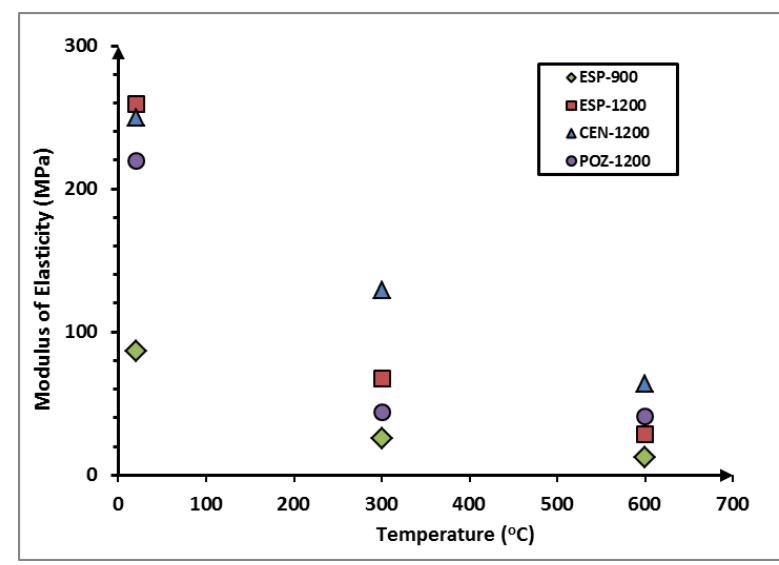

At 14 days

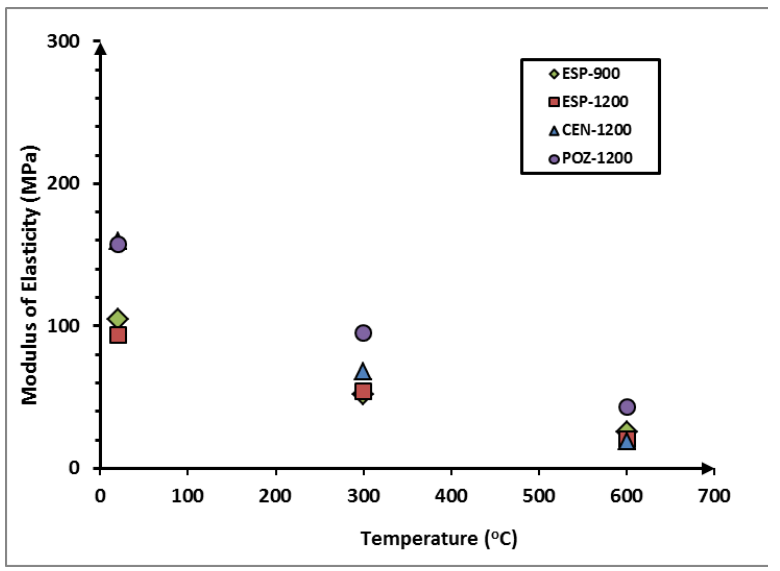

At 56 days

Figure 14: Modulus of Elasticity after exposure to elevated temperature

\section{$376 \quad 3.5$ Comparison of Compressive Strength of Different Binders}

377 In order to compare the compressive strength of hemp concrete with different types of binders

378 in the literature and the results of the present study, compressive strength versus density data

379 are collected. Figure 15 shows the density versus compressive strength behaviour of different

380 binders as given by researchers $[6,9,13,14,17,35,47,48,51,52]$. The regression lines for the lime

381 binder in the literature and the present study are shown in Figure 15. 


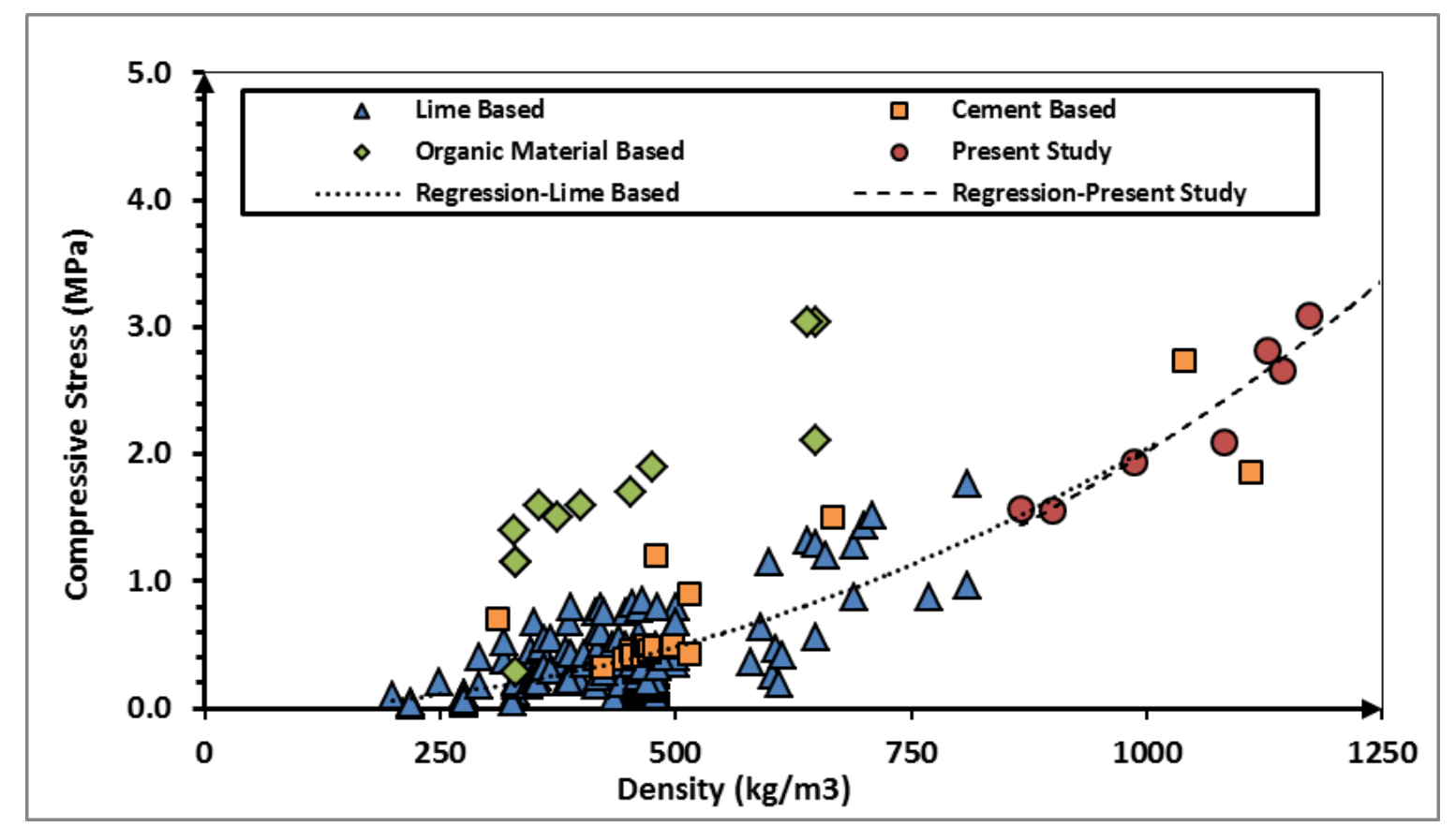

Figure 15: Comparison of Binders

382 Figure 15 concludes that starch binder gave higher compressive strengths relative to other

383 inorganic binders such as cement, lime, and cenosphere binder. The compressive strength of

384 cement binder is over the regression line of the lime binder. Therefore, higher strengths can be

385 achieved for particular density using a cement binder and starch. Therefore, using starch and

386 cement as alternative binders can produce hemp concrete with higher compressive strength

387 relative to the traditional lime binder. The trend lines of lime binder and present study showed

388 that performance of cenosphere binder can have similar compressive strengths relative to the

389 lime binder: data of ESP at 56 days is omitted in the regression analysis considering its

390 reduction of strength with the time.

391 Cement and lime have average embodied carbon footprint of $0.83 \mathrm{Kg}_{\mathrm{CO} 2} / \mathrm{Kg}$ and $0.7 \mathrm{Kg} \mathrm{CO} / \mathrm{Kg}$,

392 respectively [18]; and have average embodied energy of $4.6 \mathrm{MJ} / \mathrm{Kg}$ and $5.3 \mathrm{MJ} / \mathrm{Kg}$,

393 respectively. However, starch is an organic material which fire performance is not good as

394 other inorganic binders such as lime, cement, slag etc. In other hand, even though cement is an

395 alternative inorganic binder, it has a higher $\mathrm{CO}_{2}$ emission than lime and reduces the 
sustainability of hemp concrete. The cenosphere binders used in the present study is made of supplementary cementitious materials such as cenosphere (top fly ash), fly ash, silica fume and

398 slag which are by-products and doesn't emit large amount of $\mathrm{CO}_{2}$ or have higher embodied energy as cement or lime [23-25]. In addition, fly ash and slag binders with alkali activation

400 have lower $\mathrm{CO}_{2}$ emission and embodied energy relative to cement-based binders [26,27]. Thus,

401 the study shows that binder with suitable cenosphere can have similar compressive strengths

402 to the lime binder and can be a more sustainable alternative to the lime binder.

\subsection{FTIR analysis of the binders}

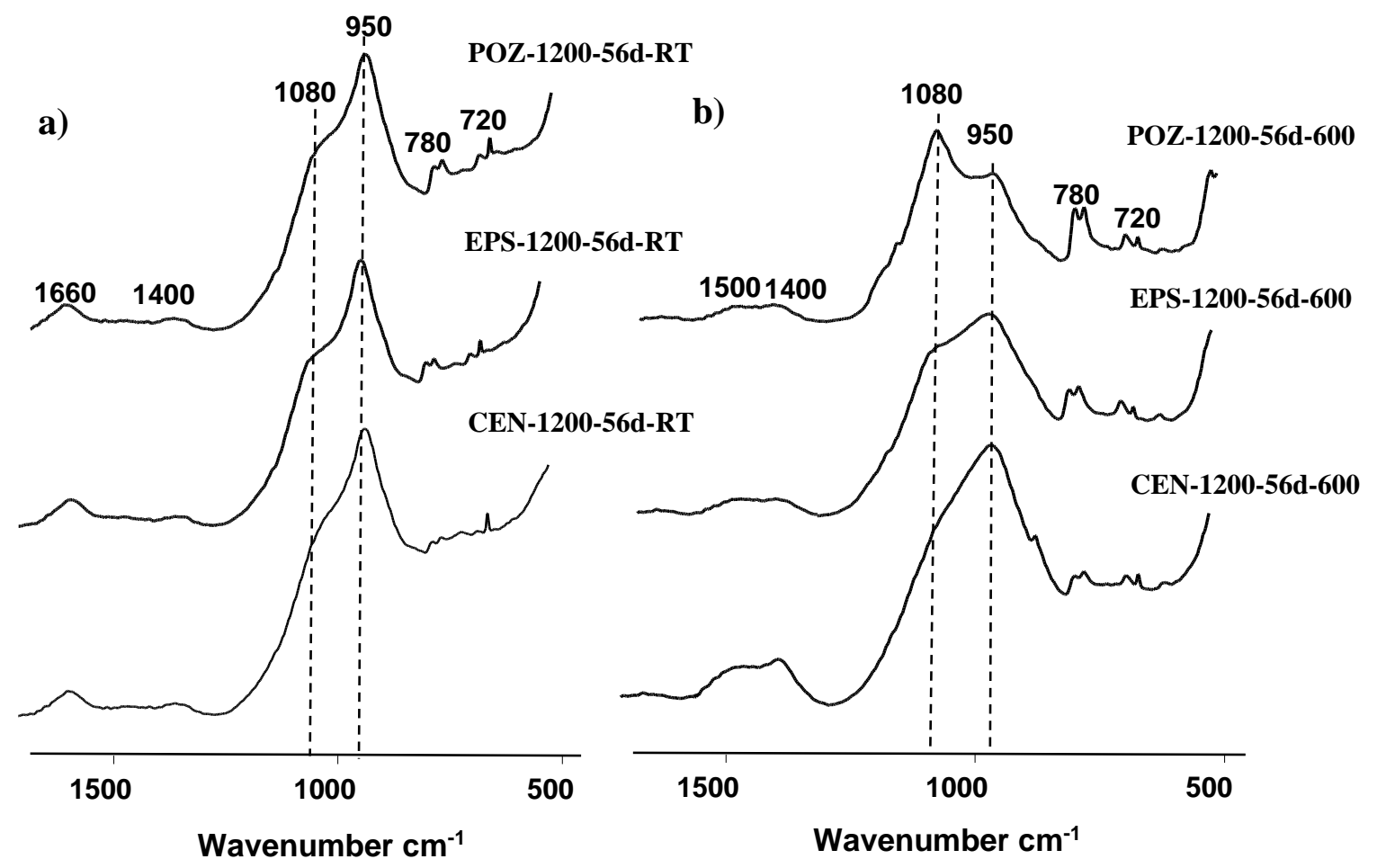

Figure 16. FTIR results of binders

404 The band around $720 \mathrm{~cm}^{-1}$ is known to be related to aluminosilicate ring structures [53] and 405 can be used to compare the zeolite phases formed in samples [54,55] and the bands at about $406780 \mathrm{~cm}^{-1}$ are related to $\mathrm{Al}-\mathrm{O}$ vibrations in $\mathrm{Al}_{2} \mathrm{O}_{3}$ structures [56,57]. The position of the band 407 around $950 \mathrm{~cm}^{-1}$ and $1080 \mathrm{~cm}^{-1}$ gives an indication of $\mathrm{Si}-\mathrm{O}$ absorption band in $\mathrm{C}-\mathrm{S}-\mathrm{H}$ and $\mathrm{N}-$ 
408 A-S-H gels (at $960 \mathrm{~cm}^{-1}$ mainly related to C-S-H and at $1080 \mathrm{~cm}^{-1}$ mainly associated with for

$409 \mathrm{~N}-\mathrm{A}-\mathrm{S}-\mathrm{H})$ [58]. The peaks at $1400 \mathrm{~cm}^{-1}$ have been attributed to asymmetric stretching of Al-

$410 \mathrm{O} / \mathrm{Si}-\mathrm{O}$ bonds [59]. The band at about $1500 \mathrm{~cm}^{-1}$ is related to the presence of sodium carbonate

411 [60], and the band around $1660 \mathrm{~cm}^{-1}$ is related to bending vibration of water.

412 The FTIR spectra of all samples are similar at room temperature. However, there are

413 differences between the FTIR results after heating samples at $600^{\circ} \mathrm{C}$. The intensity of the N-A-

$414 \mathrm{~S}-\mathrm{H}$ band at $1080 \mathrm{~cm}^{-1}$ increases for POZ at $600{ }^{\circ} \mathrm{C}$ and it remain unchanged for CEN and ESP.

415 The intensity of the C-S-H gel at $960 \mathrm{~cm}^{-1}$ drops in all samples. That is because geopolymer 416 gels (N-A-S-H) are more resistant to the elevated temperature than C-S-H gels [61]. The 417 intensity drops at $960 \mathrm{~cm}^{-1}$ is larger in POZ and EPS samples, but it is very small in the CEN 418 sample. In overall, CEN binder showed more resistant to elevated temperature relative to ESP, 419 POZ in term of C-S-H.

\subsection{TGA Analysis}

421 The thermal stability of hemp concrete is characterised by exposing the ground sample to 422 elevated temperature of $1000^{\circ} \mathrm{C}$. Thermal-gravimetric (TG) and reaction rate curves of hemp concrete samples are shown in Figure 17. In general, the mass loss percentage of all samples remains around $20 \%$ wt with a marginally higher mass loss of ESP-900 owing to its lower density. There are three major changes during TGA analysis which correspond to physical water evaporation $\left(100-200^{\circ} \mathrm{C}\right)$, thermal degradation of hemp (between $\left.400-600^{\circ} \mathrm{C}\right)[62]$ and the third degradation at high temperature (over $800^{\circ} \mathrm{C}$ ). Similar trends were found with ESP900, ESP-1200 and POZ-1200, but the second degradation of CEN-1200 was milder with the reaction rate half of those of ESP-1200 and POZ-1200. The lower degradation of hemp in CEN4301200 may explain its high compressive strength compared to ESP-1200 and POZ-1200 after 431 fire exposure (Figure 11). CEN-1200 also possesses a high reaction rate (as high as $0.06 \% /{ }^{0} \mathrm{C}$ ) 
432 at high temperature (over $800^{\circ} \mathrm{C}$ ) which was not captured from the fire exposure conducted in 433 this paper.

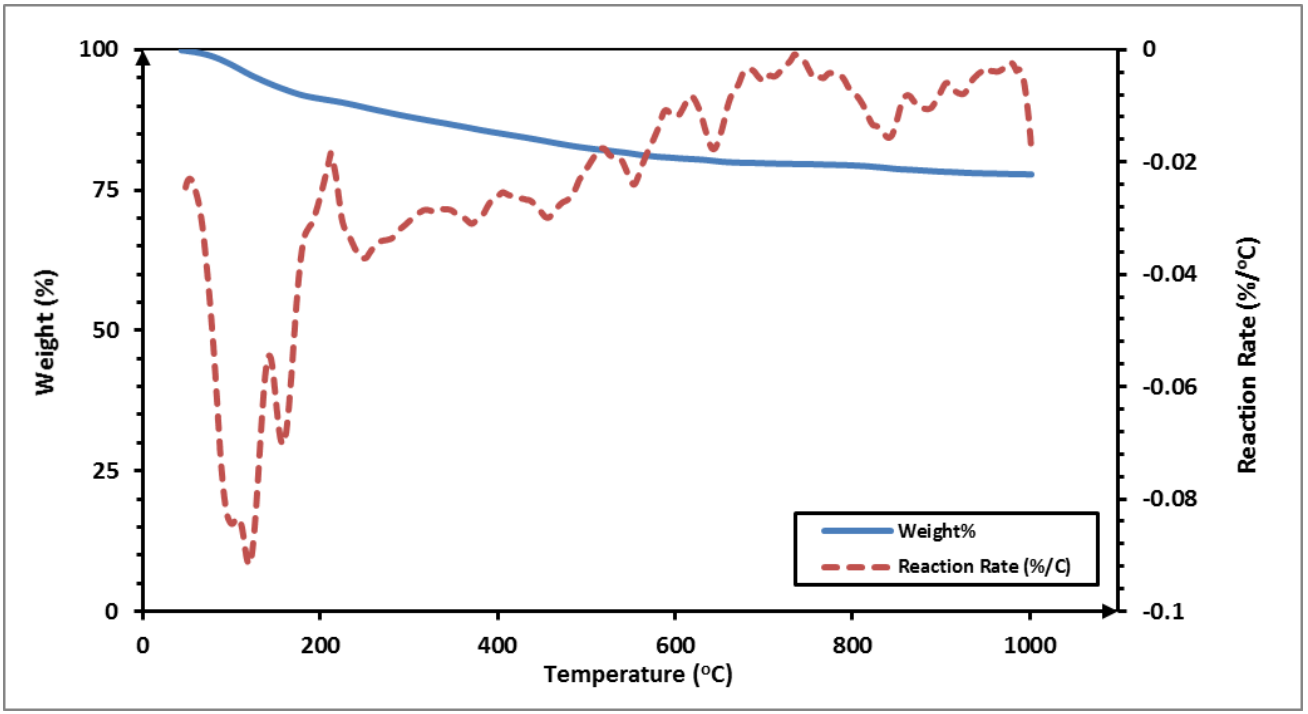

a.) ESP-900-56d

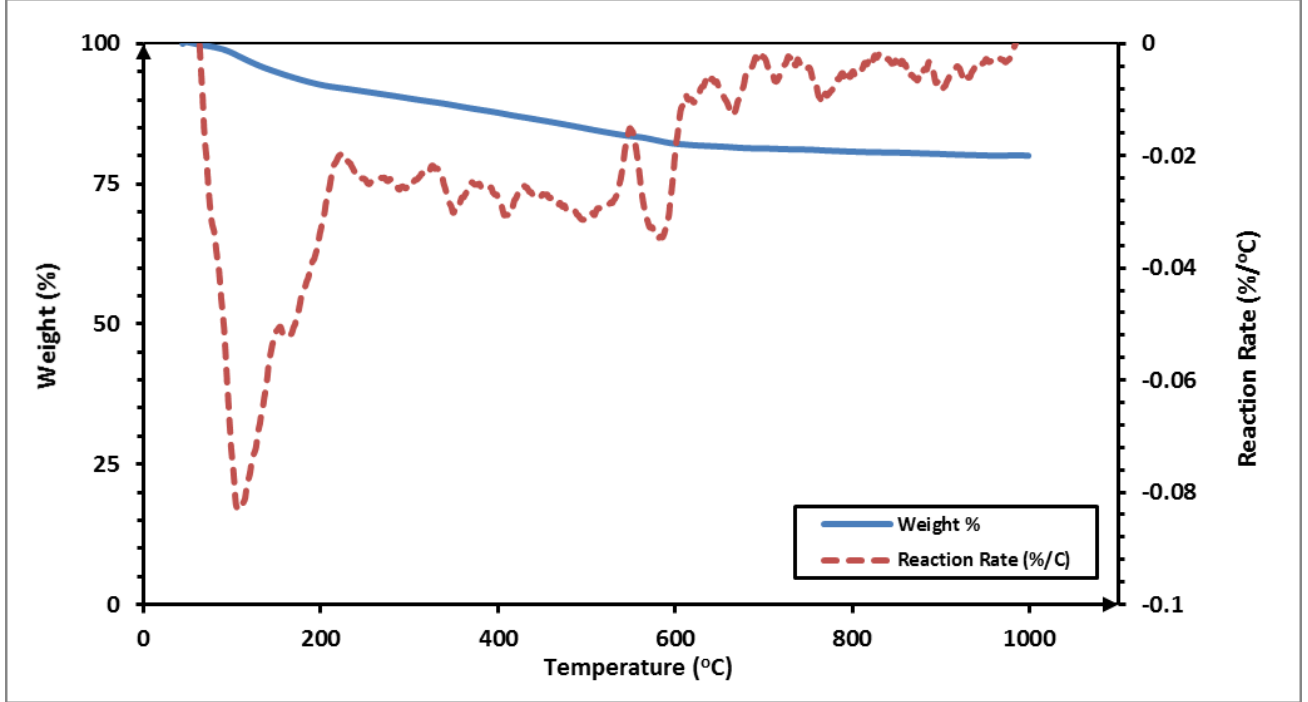

b.) ESP-1200-56d 


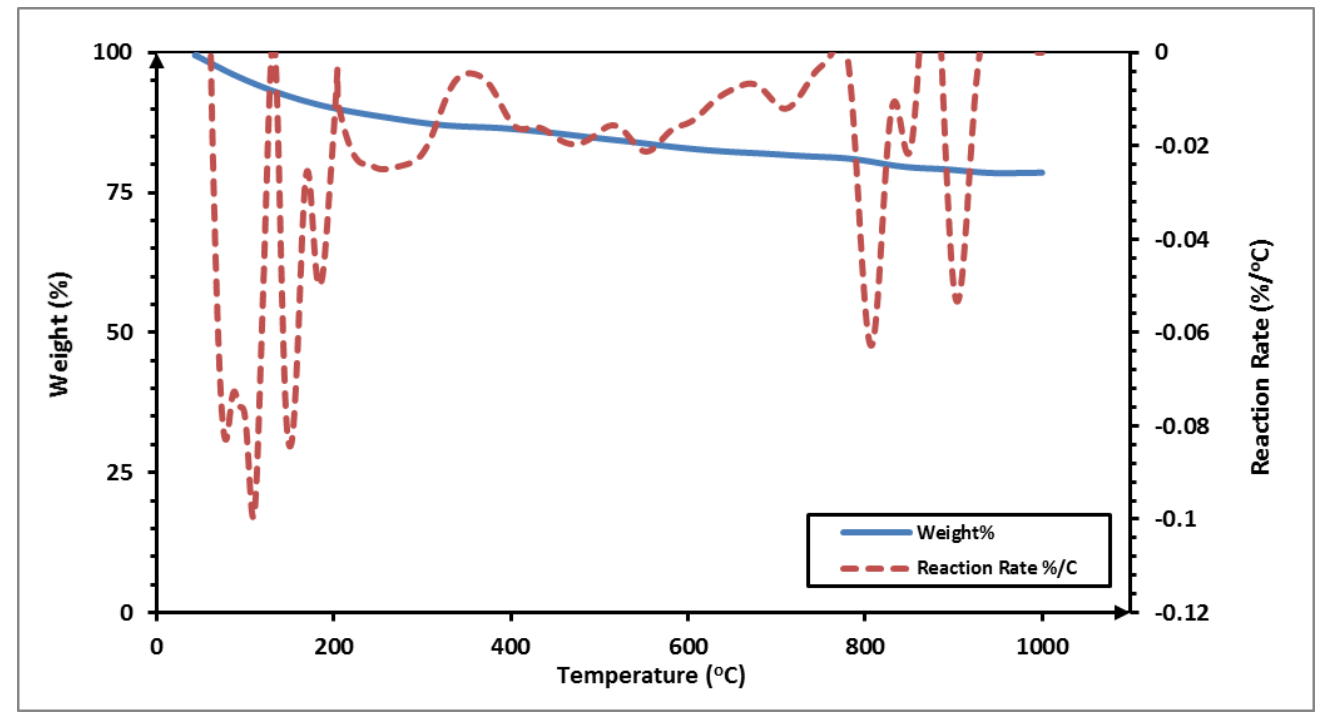

c.) CEN-1200-56d

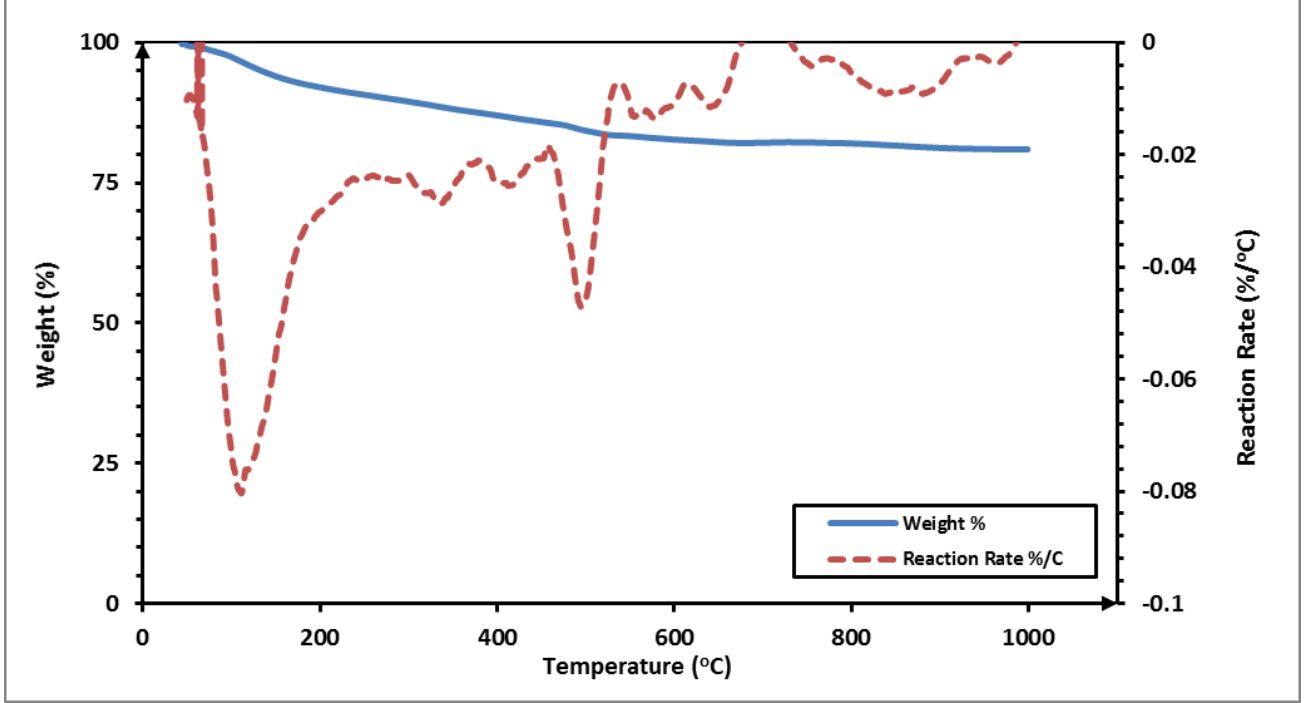

d.) POZ-1200-56d

Figure 17: Thermal-gravimetric (TG) and reaction rate curves of hemp concrete

434 The difference of mechanical performance at elevated temperature couldn't be explained using 435 TGA and FTIR results since CEN showed relative good performance in TGA and FTIR though 436 POZ mix showed higher elastic modulus, a similar compressive strength of CEN after exposed 437 to higher temperature at 56 days. One reason behind better performance of POZ can be due to 438 formation of geopolymer N-A-S-H gel which can enhance the strength and elastic modulus as 439 well as resistance to the elevated temperature. Also, as shown in Error! Reference source not 440 found., POZ has the lowest true density and similar mass of $99.8 \mathrm{~kg}$ is used for the mixes. 441 Therefore, the volume of POZ is higher than of other mixes which is $0.3 \mathrm{~m}^{3}$ per $1 \mathrm{~m}^{3}$ of hemp 
442 concrete though it is $0.16 \mathrm{~m}^{3}$ and $0.12 \mathrm{~m}^{3}$ for ESP and CEN, respectively. Therefore, POZ mix

443 has a higher binder content relative to other mixes and authors suggested that can be a reason

444 for better performance of POZ for elevated temperature and RT at 56 days even though CEN

445 shows better characteristics in FTIR and TGA analysis.

\section{Conclusions}

447 The results on compressive strength concluded that compressive strength of heated and non-

448 heated samples is dependent on type of cenosphere, density and the age of hemp concrete.

449 Modulus of elasticity results followed a similar trend of compressive strength results: Modulus

450 of elasticity reduced exponentially with the increase of temperature and age, type of cenosphere

451 and density. POZ-1200 showed a higher elastic modulus at different temperatures at 56 days.

452 For ESP binder, compressive strength decreases with the time though compressive strength of

453 CEN and POZ binders increases with the time. As stated in literature, failure in outer-shell

454 structure of cenosphere due to alkali reaction and creation of shell-less voids and cracks can be

455 the reason behind reduction in mechanical properties of ESP binder. However, the same

456 phenomena didn't observe in other mixes. Even though compressive strength of binders was

457 increased with the time for CEN and POZ mixes, compressive strength of hemp concrete was

458 decreased with the time. Therefore, it is important to observe the long-term behaviour of

459 cenosphere based binders as well as hemp concrete considering the long-term performance of

460 the materials.

461 Stress-strain relationship of samples concluded that behaviour was not brittle, and samples

462 were able to undergo large deformation at room temperature. The stress-strain behaviour vary

463 dependant on density and age of samples. The samples with a lower density can undergo large

464 deformation which is suitable for internal and external claddings. 
465 Regarding thermal stability, all samples showed a consistency with the mass loss of $20 \%$ with 466 three stages of degradation. That is due to the similar quantity of hemp in the mixes.

467 Thermogravimetric analysis of samples at 56 days showed the correlation between the lower 468 degradation rate at $400-600^{\circ} \mathrm{C}$ of $\mathrm{CEN}-1200$ and its higher compressive strength after exposure 469 to $600^{\circ} \mathrm{C}$. FTIR analysis showed that at high-temperature C-S-H get degraded notably for all 470 sample except CEN mix. Also, geopolymer N-A-S-H gel formation was observed for POZ at $600{ }^{\circ} \mathrm{C}$. In overall, FTIR analysis showed that CEN has a higher resistance than other mixes. The better performance of POZ may due to formation of N-A-S-H gel and higher binder content relative to other mixes due to its lower particle density.

474 The study showed cenosphere binder can achieve compressive strength similar to the lime binder while having a lower embodied energy and carbon emission relative to cement or lime binder. Thus, the study showed that an alkali-activated cenosphere binder has the potential to

477 be an alternative sustainable binder to the traditional lime binder while satisfying the mechanical properties. Authors suggest more experimental program using different mix proportions for alkali-activated binders and geopolymer binders while considering cost of cenosphere in order established an economical and more sustainable binder for hemp concrete 481 for future studies.

\section{Acknowledgement}

483 The authors wish to thank Dr. Jinghan Lu, Ms Tian Tang, Ms Allyssa Estacio, Mr Xiang Liao, 484 Ms Elizabeth Stavraski, Mr Steve Adam, Mr Ran Wei, Ms Liying Ren and Ms Yangxi Chu for 485 their assistance in the experimental program. This research was funded by Australian Research 486 Council (ARC) grant through Industrial Transformation Training Centres grant, ARC Centre 487 for Advanced Manufacturing of Prefabricated Buildings (IC150100023) and Discovery Early 488 Career Researcher Award (DE190100217). This work is performed in part at the Materials 
Victorian Node of the Australian National Fabrication Facility (ANFF).

\section{Reference}

[1] L. Kidalova, N. Stevulova, E. Terpakova, A. Sicakova, Utilization of alternative materials in lightweight composites, J. Clean. Prod. 34 (2012) 116-119. doi:https://doi.org/10.1016/j.jclepro.2012.01.031.

[2] M. Bell, The Potential of Hemp: A new approach to the material and its use within the construction industry, 2012.

[3] U. Dhakal, U. Berardi, M. Gorgolewski, R. Richman, Hygrothermal performance of hempcrete for Ontario (Canada) buildings, J. Clean. Prod. 142 (2017) 3655-3664. doi:https://doi.org/10.1016/j.jclepro.2016.10.102.

[4] T.S. Kiessé, A. Ventura, H.M.G. van der Werf, B. Cazacliu, R. Idir, Andrianandraina, Introducing economic actors and their possibilities for action in LCA using sensitivity analysis: Application to hemp-based insulation products for building applications, J. Clean. Prod. 142 (2017) 3905-3916. doi:https://doi.org/10.1016/j.jclepro.2016.10.069.

[5] D.M.A. Huiskes, A. Keulen, Q.L. Yu, H.J.H. Brouwers, Design and performance evaluation of ultra-lightweight geopolymer concrete, Mater. Des. 89 (2016) 516-526. doi:10.1016/j.matdes.2015.09.167.

[6] S. Benfratello, C. Capitano, G. Peri, G. Rizzo, G. Scaccianoce, G. Sorrentino, Thermal and structural properties of a hemp-lime biocomposite, Constr. Build. Mater. 48 (2013) 745-754. doi:10.1016/j.conbuildmat.2013.07.096.

[7] F. Collet, S. Prétot, Thermal conductivity of hemp concretes: Variation with formulation, density and water content, Constr. Build. Mater. 65 (2014) 612-619.

[8] Y. Florentin, D. Pearlmutter, B. Givoni, E. Gal, A life-cycle energy and carbon analysis of hemp-lime bio-composite building materials, Energy Build. 156 (2017) 293-305. doi:10.1016/j.enbuild.2017.09.097.

[9] A. Shea, M. Lawrence, P. Walker, Hygrothermal performance of an experimental hemplime building, Constr. Build. Mater. $36 \quad$ (2012) 270-275. doi:10.1016/j.conbuildmat.2012.04.123.

[10] C. Maalouf, C. Ingrao, F. Scrucca, T. Moussa, A. Bourdot, C. Tricase, A. Presciutti, F. Asdrubali, An energy and carbon footprint assessment upon the usage of hemp-lime concrete and recycled-PET façades for office facilities in France and Italy, J. Clean. Prod. 170 (2018) 1640-1653. doi:https://doi.org/10.1016/j.jclepro.2016.10.111.

[11] R. Busbridge, R. Rhydwen, An investigation of the thermal properties of hemp and clay monolithic walls, (2010).

[12] A. Arrigoni, R. Pelosato, P. Melià, G. Ruggieri, S. Sabbadini, G. Dotelli, Life cycle assessment of natural building materials: the role of carbonation, mixture components and transport in the environmental impacts of hempcrete blocks, J. Clean. Prod. 149 (2017) 1051-1061. doi:https://doi.org/10.1016/j.jclepro.2017.02.161.

[13] G. Balčiūnas, S. Vèjelis, S. Vaitkus, A. Kairyte, Physical Properties and Structure of Composite Made by Using Hemp Hurds and Different Binding Materials, Procedia Eng. 57 (2013) 159-166. doi:10.1016/j.proeng.2013.04.023.

[14] C. Niyigena, S. Amziane, A. Chateauneuf, L. Arnaud, L. Bessette, F. Collet, C. Lanos, G. Escadeillas, M. Lawrence, C. Magniont, S. Marceau, S. Pavia, U. Peter, V. Picandet, M. 
Sonebi, P. Walker, Variability of the mechanical properties of hemp concrete, Mater. Today Commun. 7 (2016) 122-133. doi:10.1016/j.mtcomm.2016.03.003.

[15] R. Walker, S. Pavia, R. Mitchell, Mechanical properties and durability of hemp-lime concretes, Constr. Build. Mater. $61 \quad$ (2014) 340-348. doi:10.1016/j.conbuildmat.2014.02.065.

[16] E. Sassoni, S. Manzi, A. Motori, M. Montecchi, M. Canti, Novel sustainable hemp-based composites for application in the building industry: Physical, thermal and mechanical characterization, Energy Build. 77 (2014) 219-226. doi:10.1016/j.enbuild.2014.03.033.

[17] N. Stevulova, L. Kidalova, J. Cigasova, J. Junak, A. Sicakova, E. Terpakova, Lightweight Composites Containing Hemp Hurds, Procedia Eng. 65 (2013) 69-74. doi:10.1016/j.proeng.2013.09.013.

[18] G. Hammond, C. Jones, F. Lowrie, P. Tse, Inventory of carbon \& energy: ICE, Sustainable Energy Research Team, Department of Mechanical Engineering, University of Bath Bath, 2008.

[19] B.V. Reddy, K.S. Jagadish, Embodied energy of common and alternative building materials and technologies, Energy Build. 35 (2003) 129-137.

[20] K. Ip, A. Miller, Life cycle greenhouse gas emissions of hemp-lime wall constructions in the UK, Resour. Conserv. Recycl. 69 (2012) 1-9. doi:10.1016/j.resconrec.2012.09.001.

[21] A. Arizmendi-Morquecho, A. Chávez-Valdez, J. Alvarez-Quintana, High temperature thermal barrier coatings from recycled fly ash cenospheres, Appl. Therm. Eng. 48 (2012) 117-121. doi:10.1016/j.applthermaleng.2012.05.004.

[22] A. Hanif, S. Diao, Z. Lu, T. Fan, Z. Li, Green lightweight cementitious composite incorporating aerogels and fly ash cenospheres - Mechanical and thermal insulating properties, Constr. Build. Mater. $116 \quad$ (2016) 422-430. doi:10.1016/j.conbuildmat.2016.04.134.

[23] C. (Catherine E.L. De Wolf, Material quantities in building structures and their environmental impact, Thesis, Massachusetts Institute of Technology, 2014. http://dspace.mit.edu.ezp.lib.unimelb.edu.au/handle/1721.1/91298 (accessed February 23, 2018).

[24] C.C.E.L. De Wolf, Low carbon pathways for structural design: embodied life cycle impacts of building structures, Massachusetts Institute of Technology, 2017.

[25] K. Kupwade-Patil, C. De Wolf, S. Chin, J. Ochsendorf, A.E. Hajiah, A. Al-Mumin, O. Büyüköztürk, Impact of Embodied Energy on materials/buildings with partial replacement of ordinary Portland Cement (OPC) by natural Pozzolanic Volcanic Ash, J. Clean. Prod. 177 (2018) 547-554. doi:10.1016/j.jclepro.2017.12.234.

[26] E. Jamieson, B. McLellan, A. van Riessen, H. Nikraz, Comparison of embodied energies of Ordinary Portland Cement with Bayer-derived geopolymer products, J. Clean. Prod. 99 (2015) 112-118. doi:10.1016/j.jclepro.2015.03.008.

[27] B.C. McLellan, R.P. Williams, J. Lay, A. van Riessen, G.D. Corder, Costs and carbon emissions for geopolymer pastes in comparison to ordinary portland cement, J. Clean. Prod. 19 (2011) 1080-1090. doi:10.1016/j.jclepro.2011.02.010.

[28] Q.T. Nguyen, T. Ngo, P. Tran, P. Mendis, L. Aye, S.K. Baduge, Fire resistance of a prefabricated bushfire bunker using aerated concrete panels, Constr. Build. Mater. 174 (2018) 410-420.

[29] AS 1530.4, Methods for fire tests on building materials, components and structures Fireresistance test of elements of construction, Standards Association of New Zealand, Sydney, Australia., 2005.

[30] Lubos, Gregor, Performance of hempcrete walls subjected to a prescribed Fire Curve.pdf, Victoria University, 2014. 
[31] EN 13823, Reaction To Fire Tests For Building Products - Building Products Excluding Floorings Exposed To The Thermal Attack By A Single Burning Item, European Committee for Standardization, Brussels, Belgium, 2010.

[32] P. Daly, P. Ronchetti, T. Woolley, Hemp Lime Bio-composite as a Building Material Irish Construction, Environ. Prot. Agency Irel. (2012).

[33] W. Stanwix, A. Sparrow, The hempcrete book: designing and building with hemp-lime, Green Books Cambridge, UK:, 2014.

[34] BS EN 1365-1, Fire resistance tests for loadbearing elements. Walls, British Standard Institute, London, UK, 1999.

[35] L. Arnaud, E. Gourlay, Experimental study of parameters influencing mechanical properties of hemp concretes, Constr. Build. Mater. 28 (2012) 50-56. doi:10.1016/j.conbuildmat.2011.07.052.

[36] N. Stevulova, L. Kidalova, J. Junak, J. Cigasova, E. Terpakova, Effect of Hemp Shive Sizes on Mechanical Properties of Lightweight Fibrous Composites, Procedia Eng. 42 (2012) 496-500. doi:10.1016/j.proeng.2012.07.441.

[37] AS 1141.6, Methods for sampling and testing aggregates Particle density and water absorption of coarse aggregate - Weighing-in-water method, Standards Association of Australia, Sydney, Australia., 2000.

[38] AS 1012.3.5, Methods of testing concrete - Determination of properties related to the consistency of concrete - Slump flow, T500 and J-ring test, Standards Association of Australia, NSW, Australia, 2015.

[39] AS 3582.2, Supplementary cementitious materials for use with portland and blended cement - Slag - Ground granulated iron blast-furnace, Standards Association of Australia, NSW, Australia, 2001.

[40] AS/NZS 3582.3, Supplementary cementitious materials for use with portland and blended cement-amorphous silica, Standards Association of Australia; Standards Association of New Zealand, NSW, Australia, 2002.

[41] D. Sedan, C. Pagnoux, A. Smith, T. Chotard, Mechanical properties of hemp fibre reinforced cement: Influence of the fibre/matrix interaction, J. Eur. Ceram. Soc. 28 (2008) 183-192. doi:10.1016/j.jeurceramsoc.2007.05.019.

[42] T. Drzymała, W. Jackiewicz-Rek, M. Tomaszewski, A. Kuś, J. Gałaj, R. Šukys, Effects of high temperature on the properties of high performance concrete (HPC), Procedia Eng. 172 (2017) 256-263.

[43] Z. Zhang, J.L. Provis, A. Reid, H. Wang, Geopolymer foam concrete: An emerging material for sustainable construction, Constr. Build. Mater. 56 (2014) 113-127. doi:10.1016/j.conbuildmat.2014.01.081.

[44] J.-Y. Wang, M.-H. Zhang, W. Li, K.-S. Chia, R.J.Y. Liew, Stability of cenospheres in lightweight cement composites in terms of alkali-silica reaction, Cem. Concr. Res. 42 (2012) 721-727. doi:10.1016/j.cemconres.2012.02.010.

[45] D. Montgomery, S. Diamond, The influence of fly ash cenospheres on the details of cracking in flyash-bearing cement pastes, Cem. Concr. Res. 14 (1984) 767-775.

[46] K. Senthamarai Kannan, L. Andal, M. Shanmugasundaram, An investigation on strength development of cement with cenosphere and silica fume as pozzolanic replacement, Adv. Mater. Sci. Eng. 2016 (2016).

[47] M. Chabannes, E. Garcia-Diaz, L. Clerc, J.-C. Bénézet, Studying the hardening and mechanical performances of rice husk and hemp-based building materials cured under natural and accelerated carbonation, Constr. Build. Mater. 94 (2015) 105-115. doi:10.1016/j.conbuildmat.2015.06.032. 
[48] E.A.J. Hirst, P. Walker, K.A. Paine, T. Yates, Characteristics of low-density hemp-lime building materials, Proc. Inst. Civ. Eng. - Constr. Mater. 165 (2012) 15-23. doi:10.1680/coma.1000021.

[49] T.-T. Nguyen, V. Picandet, S. Amziane, C. Baley, Influence of compactness and hemp hurd characteristics on the mechanical properties of lime and hemp concrete, Eur. J. Environ. Civ. Eng. 13 (2009) 1039-1050. doi:10.1080/19648189.2009.9693171.

[50] ASTM C 1018, Standard test method for flexural toughness and first crack strength of fibre reinforced concrete (Using beam with third-point loading), American Society of Testing and Materials, Philadelphia, United States, 1998.

[51] Hempcrete Installation Facts Sheet, Hempcrete Aust. Pty Ltd. (2014). http://www.hempcrete.com.au/index.php?option=com_content\&view=article\&id=2\&Ite mid=3 (accessed March 14, 2017).

[52] E. Sassoni, S. Manzi, A. Motori, M. Montecchi, M. Canti, Experimental study on the physical-mechanical durability of innovative hemp-based composites for the building industry, Energy Build. 104 (2015) 316-322. doi:10.1016/j.enbuild.2015.07.022.

[53] W. Mozgawa, The relation between structure and vibrational spectra of natural zeolites, J. Mol. Struct. 596 (2001) 129-137.

[54] C.A. Rees, Mechanisms and kinetics of gel formation in geopolymers, PhD Thesis, 2007.

[55] C.A. Rees, J.L. Provis, G.C. Lukey, J.S. Van Deventer, The mechanism of geopolymer gel formation investigated through seeded nucleation, Colloids Surf. Physicochem. Eng. Asp. 318 (2008) 97-105.

[56] W.K.W. Lee, J.S.J. Van Deventer, Use of infrared spectroscopy to study geopolymerization of heterogeneous amorphous aluminosilicates, Langmuir. 19 (2003) 8726-8734.

[57] C.A. Rees, J.L. Provis, G.C. Lukey, J.S. van Deventer, Attenuated total reflectance fourier transform infrared analysis of fly ash geopolymer gel aging, Langmuir. 23 (2007) 81708179.

[58] I. García-Lodeiro, A. Palomo, A. Fernández-Jiménez, D.E. Macphee, Compatibility studies between NASH and CASH gels. Study in the ternary diagram $\mathrm{Na2O}-\mathrm{CaO}-$ Al2O3-SiO2-H2O, Cem. Concr. Res. 41 (2011) 923-931.

[59] X. Guo, H. Shi, W.A. Dick, Compressive strength and microstructural characteristics of class C fly ash geopolymer, Cem. Concr. Compos. 32 (2010) 142-147.

[60] P.N. Lemougna, K.J. MacKenzie, U.C. Melo, Synthesis and thermal properties of inorganic polymers (geopolymers) for structural and refractory applications from volcanic ash, Ceram. Int. 37 (2011) 3011-3018.

[61] N.K. Lee, K.T. Koh, G.H. An, G.S. Ryu., Influence of binder composition on the gel structure in alkali activated fly ash/slag pastes exposed to elevated temperatures, Ceram. Int. 43 (2017) 2471-2480. doi:10.1016/j.ceramint.2016.11.042.

[62] I. Netinger Grubeša, B. Marković, A. Gojević, J. Brdarić, Effect of hemp fibers on fire resistance of concrete, Constr. Build. Mater. 184 (2018) 473-484. doi:10.1016/j.conbuildmat.2018.07.014. 